\title{
Article \\ An Effective Method for InSAR Mapping of Tropical Forest Degradation in Hilly Areas
}

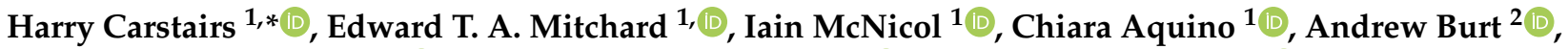

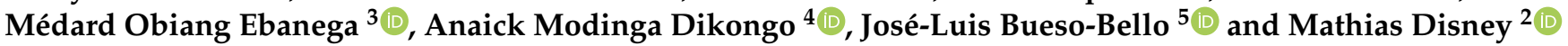 \\ 1 School of Geosciences, The University of Edinburgh, Edinburgh EH8 3FF, UK; \\ edward.mitchard@ed.ac.uk (E.T.A.M.); I.McNicol@ed.ac.uk (I.M.); Chiara.Aquino@ed.ac.uk (C.A.) \\ 2 Department of Geography, University College London, London WC1E 6BT, UK; a.burt@ucl.ac.uk (A.B.); \\ mathias.disney@ucl.ac.uk (M.D.) \\ 3 School of Geography, Omar Bongo University, Libreville, Gabon; obiang_medard@yahoo.fr \\ 4 Agence Gabonais d'Etudes et d'Observations Spatiales, Libreville, Gabon; anaick.modinga@ageos.ga \\ 5 German Aerospace Center (DLR), Microwaves and Radar Institute, Oberpfaffenhofen, \\ 82234 Weßling, Germany; Jose-Luis.Bueso-Bello@dlr.de \\ * Correspondence: Harry.Carstairs@ed.ac.uk
}

Citation: Carstairs, H.; Mitchard, E.T.A.; McNicol, I.; Aquino, C.; Burt, A.; Ebanega, M.O.; Dikongo, A.M.; Bueso-Bello, J.-L.; Disney, M. An Effective Method for InSAR Mapping of Tropical Forest Degradation in Hilly Areas. Remote Sens. 2022, 14, 452. https://doi.org/10.3390/ rs14030452

Academic Editors: Johannes Reiche, Jörg Haarpaintner, Manuela Hirschmugl and Janik Deutscher

Received: 4 November 2021

Accepted: 13 January 2022

Published: 18 January 2022

Publisher's Note: MDPI stays neutral with regard to jurisdictional claims in published maps and institutional affiliations.

Copyright: (C) 2022 by the authors. Licensee MDPI, Basel, Switzerland. This article is an open access article distributed under the terms and conditions of the Creative Commons Attribution (CC BY) license (https:// creativecommons.org/licenses/by/ $4.0 /)$.

\begin{abstract}
Current satellite remote sensing methods struggle to detect and map forest degradation, which is a critical issue as it is likely a major and growing source of carbon emissions and biodiveristy loss. TanDEM-X InSAR phase height $\left(h_{\phi}\right)$ is a promising variable for measuring forest disturbances, as it is closely related to the mean canopy height, and thus should decrease if canopy trees are removed. However, previous research has focused on relatively flat terrains, despite the fact that much of the world's remaining tropical forests are found in hilly areas, and this inevitably introduces artifacts in sideways imaging systems. In this paper, we find a relationship between $h_{\phi}$ and aboveground biomass change in four selectively logged plots in a hilly region of central Gabon. We show that minimising multilooking prior to the calculation of $h_{\phi}$ strengthens this relationship, and that degradation estimates across steep slopes in the surrounding region are improved by selecting data from the most appropriate pass directions on a pixel-by-pixel basis. This shows that TanDEM-X InSAR can measure the magnitude of degradation, and that topographic effects can be mitigated if data from multiple SAR viewing geometries are available.
\end{abstract}

Keywords: InSAR; TanDEM-X; forest degradation; biomass change; synthetic aperture radar; SAR; carbon cycle; satellite data; earth observation; DLR; X-band

\section{Introduction}

Tropical forests play a significant role in the global carbon cycle, storing approximately one-quarter of the carbon in the terrestrial biosphere [1] and performing one-third of terrestrial photosynthesis [2]. Taking into account deforestation, forest degradation, and environmental stress due to climate change, these regions are becoming a net source of carbon, which is predicted to increase in magnitude [3-6]. Monitoring the biomass dynamics of tropical forests at fine spatial scales $(<1 \mathrm{ha})$ is important if we are to estimate the magnitude of this source and predict its impact on global climate [7]. Forest degradation, in particular, is a substantial but difficult-to-quantify driver of greenhouse gas emissions [8,9]. Degradation is broadly defined as a human-driven loss of forest biomass that does not result in conversion to a non-forest state. It has been estimated that carbon emissions from degradation exceed those from deforestation in the Amazon [10], and the flux from tropical Africa could be expected to be higher still given its higher population density [5]. However, the lack of data on degradation means its spatial and temporal patterns are very poorly known. Degradation encompasses a range of disturbance types, including livestock grazing, wildfire and fuelwood extraction, but around half of tropical degradation is driven 
by selective logging [11]. This form of degradation affected approximately $20 \%$ of humid tropical forests between 2000 and 2005 [12], and has likely impacted larger areas since then, with the global area of timber producing forests estimated to have increased by $14 \%$ between 2005 and 2010 [13].

Disparate reporting practices, commercial sensitivities, and the fact that extracted timber makes up a varying fraction of biomass depletion [8] all make a bottom-up approach difficult to verify. Remote sensing is therefore well-placed to map and quantify logging consistently at a country to pantropical scale. However, remote sensing of tropical logging is also challenging due to the 'selective' nature of timber extraction, whereby only the most valuable trees are removed. Outside SE Asia, this often means removing fewer than one tree per ha (where each hectare contains many hundreds of trees larger than $10 \mathrm{~cm}$ diameter). Although additional damage is caused by site access and timber extraction, low-intensity logging still leaves the majority of forest components relatively unchanged. This necessitates high spatial resolution and high sensitivity to detect it, or harder still the difference between sustainable (e.g., following reduced impact logging protocols or FSC practices) and unsustainable or illegal logging practices [14,15]. While there are an increasing number of high-resolution optical sensors available, forest regrowth or the presence of green sub-canopy trees and vegetation can make degraded areas optically indistinguishable from intact forest within days-months of degradation events [16], and high cloud cover in the tropics reduces the probability of obtaining any useful images in this period [17].

Spaceborne synthetic aperture radar (SAR) systems are advantageous in their ability to image the Earth through cloud cover, allowing monthly to weekly sequences of high-resolution images [18]. This has led to an increased focus on SAR for forest change detection through various mechanisms including backscatter statistics [19] and shadowing effects [20]. An additional advantage of SAR is that the phase of the scattered signal can be measured-this is of particular interest in high-biomass tropical forests where relationships between aboveground biomass (AGB) and backscattered intensity saturate [21,22]. With SAR interferometry (InSAR) it is possible to relate the phase difference between two images to the relative vertical height of the scatterers within each resolution cell: this is termed the interferometric phase height $\left(h_{\phi}\right)$. Changes in $h_{\phi}$ should, in theory, relate strongly to the magnitude of a disturbance event within a resolution cell. However, this technique is possible only if the phase contribution from the scattering components is stable across the temporal baseline separating the two images. In a tropical forest, wind and rain can cause canopy scatterers to decorrelate within minutes [23], so the temporal baseline must be close to zero for successful extraction of $h_{\phi}$. The TanDEM-X SAR interferometer (TDX) achieves this using two twin satellites orbiting in a helix formation [24], meaning images from different angles are captured simultaneously.

Previous work has shown that TDX $h_{\phi}$ is a promising metric for measuring changes in forest structure. It has been shown that the temporal variability of $h_{\phi}$ in an undisturbed tropical forest is modest (standard deviation $0.5 \mathrm{~m}$ ) and uncorrelated with weather conditions [25]. In another study, $h_{\phi}$ decreased by several meters in 0.25 ha areas of tropical forest cleared for agriculture [26]. The same study found increases in $h_{\phi}$ for undisturbed plots over a 3.2 year period, with secondary forest plots increasing by an average of $0.8 \mathrm{~m} \mathrm{yr}^{-1}$, suggesting a sensitivity to biomass increases as well as decreases. Selective logging in the same area (Tapajos, Brazil) has been quantified using a disturbance index (DI), defined by the fraction of projected crown area removed from a 0.25 ha plot [27]. The authors used a modeling approach to show that the DI is approximately proportional to $\Delta h_{\phi} / h_{0}$, where $h_{0}$ is the mean canopy height relative to the topography. The lack of bare earth digital terrain models (DTMs) for most forested tropical areas makes it a challenge to extract $h_{0}$ from TDX data, although a method has been presented to do so using the distribution of $h_{\phi}$ in few-look interferograms [28].

While these previous studies were conducted in areas with relatively flat terrain [25,27], it is known that steep slopes have a strong effect on InSAR data [29]. This is potentially a major issue, as much of the world's forests are in steep terrain. We estimate that close to 
one-third (29\%) of the world's primary humid tropical forests are located on slopes steeper than $10^{\circ}$. We estimated this by comparing the slope of 1 arc-second resolution Shuttle Radar Topography Mission (SRTM) data [30] to a 2001 map of primary humid tropical forest cover [31], adjusted to account for forest losses between then and 2020 [32]. This estimate is likely to be conservative, considering that the true topography in these regions is masked by tree cover in the SRTM dataset. Therefore, if we aim to quantify forest degradation across the tropics, it is vital to develop methods that are reliable in hilly areas.

The aim of this work was to predict AGB loss in an area of complex terrain, such that artifacts due to strong slopes were minimised without compromising the ability to detect low levels of degradation. To this end, we posed the following two hypotheses:

- $\quad$ Firstly, that there would exist an optimal method of spatial averaging (multilooking) at which TDX $h_{\phi}$ would have the highest sensitivity to degradation;

- Secondly, that selecting only data from a single orbital pass direction on a pixel-bypixel basis would mitigate topographic effects on predictions of AGB loss.

Our hypotheses were tested using TDX data from before and after a controlled selective logging experiment in Gabon. A description of the study area and the TDX data are given in Sections 2.1 and 2.2, respectively. This is followed in Section 2.3 by details on the manual field surveys, terrestrial laser scanning (TLS) and aerial laser scanning we conducted to provide benchmark measurements of AGB change. Section 2.5 describes the processing chain used to calculate $h_{\phi}$ from co-registered TDX image pairs, while our method for aggregating changes in $h_{\phi}$ to 1 ha scale is given in Section 2.6. The methods section finishes with a theoretical description of how selecting a single-pass direction for each pixel is advantageous, alongside the algorithm we used to implement this. Our results (Section 3) show that the smallest number of multi-looks tested $(3 \times 3)$ gave the best sensitivity to degradation, and that pass selection dramatically reduces errors due to topography. Finally, in Section 4 we discuss the implications of our results for wide scale mapping of degradation and contrast our findings to recently published forest disturbance alerts derived from Sentinel-1 (S-1) C-band SAR [19] before we conclude in Section 5.

\section{Methods and Materials}

\subsection{Study Site}

The study site is located around a disused airstrip $\left(0.148^{\circ} \mathrm{S}, 12.264^{\circ} \mathrm{E}\right)$ close to the confluence of the Ivindo and Ogooué rivers in the Ogooué-Ivindo department of Gabon (Figure 1). The nearest settlement, Ivindo village, is also an operational base for logging company Rougier Gabon which holds concessions to extract timber from the surrounding forest, the primary species of commercial value being Okoumé (Aucoumea klaineana). The logging concession is certified by the Forest Stewardship Council (FSC-C144419).
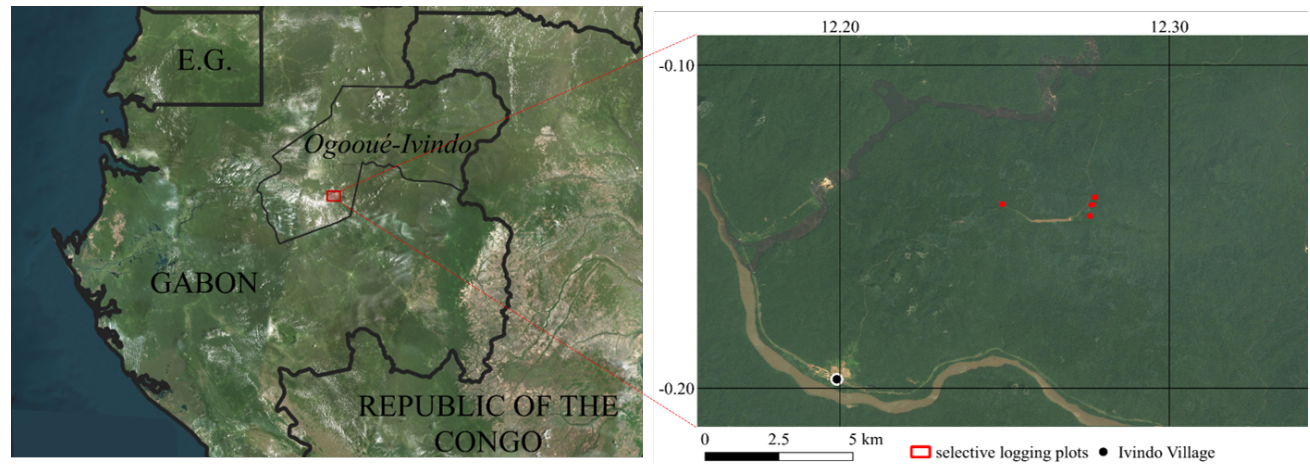

Figure 1. Location of the study site at Ivindo, Gabon. Inset shows grid coordinates in decimal degrees, and indicates the location of the four selectively logged plots in relation to Ivindo village, which is also a base for logging operations in the region. (left, Earthstar Geographics, SIO, (c) 2021 TomTom; right, (c) 2021 Landsat/Copernicus, Maxar Technologies). 
Mature forest is the dominant landcover in the region, the only exceptions being rivers and some small areas cleared for habitation, agriculture, transport and logging activities. The forest has a stem density in the range of 200 to $300 \mathrm{ha}^{-1}$, and the tallest trees generally reach heights of 40 to $50 \mathrm{~m}$. Regionally, the forest has a high biomass density and relatively low stem turnover (e.g., compared to many Amazonian areas) with annual mortality of trees $>10 \mathrm{~cm}$ diameter estimated to be about $1 \%$ [33].

Central Gabon is one of the cloudiest regions in the world [34], and its climate is characterised by a long dry season June-August, during which precipitation is below $1 \mathrm{~mm} /$ day, but extensive low cloud cover suppresses temperatures and maintains high humidity [35]. A second dry season occurs December-February. According to TRMM monthly precipitation estimates [36], annual precipitation at the study site is less than $2000 \mathrm{~mm}$ per year, and has been declining in recent years towards $1500 \mathrm{~mm}$ per year or less - a trend also confirmed by nearby ground data [37].

\subsection{TanDEM-X Acquisitions}

The TDX mission consists of twin X-band SAR satellites that orbit in close proximity to each other $(<1 \mathrm{~km}$, quantified to the nearest $\mathrm{mm})$ following a helix trajectory [24]. For each bistatic data acquisition by TDX, one satellite (the primary) acts as a transmitter-receiver while the other (the secondary) receives the signal only. The result is therefore a pair of images, representing the signals received by the two satellites. For this study, eight such pairs of images were obtained from the German Aerospace Center (DLR) in coregistered single look slant range complex (CoSSC) format. The CoSSC products were captured using stripmap mode, used horizontal polarisation both in transmission and reception $(\mathrm{HH})$, and had an azimuth resolution of approximately $3 \mathrm{~m}$ [38]. The range resolution, meanwhile, varies according to the bandwidth of the transmitted signal: those acquisitions for which a bandwidth of $150 \mathrm{MHz}$ was possible have a slant range resolution of $1.3 \mathrm{~m}$, while other acquisitions were limited to $100 \mathrm{MHz}$ and have a slant range resolution of $1.9 \mathrm{~m} \mathrm{[38].}$ Table 1 shows the dates, pass directions and bandwidths of the eight CoSSC products in chronological order, indicating also the dates of selective logging in our field plots. The effective perpendicular baseline between the satellites and the corresponding height of ambiguity (HoA; the vertical displacement equivalent to a $2 \pi$ shift in interferometric phase) are also shown [18].

Table 1. TanDEM-X (TDX) acquisition dates and imaging parameters. The baselines given here are the effective perpendicular baselines. Pass directions are given as D (descending) or A (ascending). Incidence angles are relative to vertical at the centre of each scene. HoA = Height of Ambiguity.

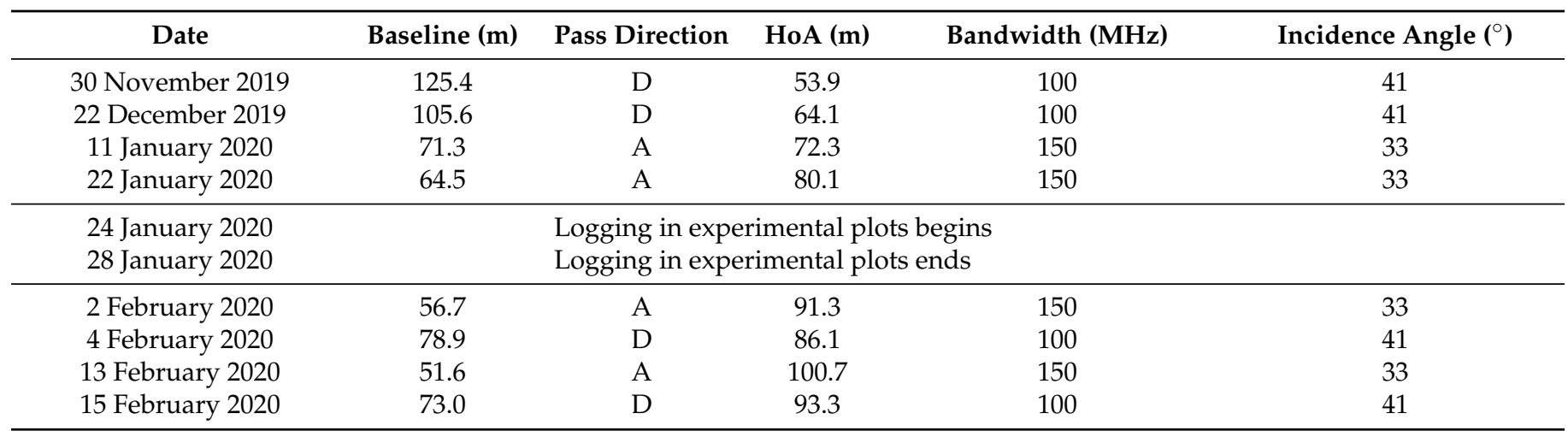


For each pass direction, there are two acquisitions before logging and two acquisitions after logging. It should be noted that the descending images were all limited to $100 \mathrm{MHz}$ bandwidth, meaning they have a slightly lower range resolution than the ascending images.

In general, if the HoA is less than or equal to the height of a tree, the interferometric phase contributions from the top and bottom of the tree would differ by over $2 \pi$ [26]. As the tree height in the study area rarely exceeded $50 \mathrm{~m}$ (our data showed the top canopy height to be less than $50 \mathrm{~m}$ for $98 \%$ of forested area), and all acquisitions have a HoA greater than this, it is unlikely that such ambiguities will affect our results. We note, however, that HoA magnitudes are smaller and thus ambiguities more likely in the pre-logging acquisitions than the post logging acquisitions, and in the descending passes than the ascending passes.

\subsection{Field Data}

Forest inventories in four 1 ha plots were conducted in August 2019 and February 2020, to estimate biomass change from controlled selective logging in January 2020. To improve the accuracy of our biomass change estimates, TLS was used to create structural models of all logged trees (prior to felling). Unoccupied aerial vehicle (UAV) laser scanning (LiDAR) data were also obtained immediately before the logging began, and then again one year later, following the removal of logs from the inventory plots and additional logging in the surrounding area. This allowed the creation of eleven control plots of 1 ha each, in which the UAV data showed no significant changes in Top Canopy Height.

\subsubsection{Forest Inventories}

Four permanent plots were established such that they were easily accessible by UAV from the disused airstrip and contained commercially viable trees. Each plot was rectangular with one side orientated within $10^{\circ}$ of North, and an area within $10 \%$ of 1 ha. The locations of the plot corners were measured by the integrated GNSS receiver of a Riegl VZ-400 terrestrial laser scanner.

For the pre-logging census, conducted in August 2019, every living tree stem with diameter at breast height $(\mathrm{DBH})$ greater than $10 \mathrm{~cm}$ was tagged and given rough coordinates $(\approx \pm 2 \mathrm{~m})$ relative to the southwest corner of the plot. At a height of $1.3 \mathrm{~m}$ along the stem from the ground a tape measure was used to determine DBH according to the RAINFOR field protocol [39]. Tree species were determined by local botanists, from which wood density was estimated using a global database [40]. In addition, each stem was inspected for structural damage, and categorised according to the approximate reduction in wood volume compared to an undamaged stem of the same size $(0,10,25,50$ or $75 \%)$. It was noted if stems were leaning, fallen or showing obvious signs of disease or parasitic damage.

In collaboration with Rougier Gabon, trees were selected for logging such that the plots would span a range of AGB change values, while also providing useful timber. The logging took place between the 24 and 28 January 2020, under special permission from Gabon's Ministry for the Protection of the Environment and Natural Resources, Forests and the Seas, removing 18 trees in total. The selected trees were felled in the direction which would cause the least damage to other trees, according to standard low-impact logging practice (the concession is certified by the Forest Stewardship Council, license FSC-C144419).

A second census was carried out at the beginning of February 2020, in which all remaining tagged trees were remeasured and reassessed for damage. At this stage, the logs remained in the plots, meaning that later damage is very likely to have occurred upon the extraction of the logs. However, the timing is appropriate for this study as it matches the acquisition of post-logging TDX images.

Wood density for each tree was estimated at the species level from a global database [41] where possible. Genus averages and local averages were used for trees where an exact species match in the database could not be found. An allometric equation based on destructive harvests across the tropics [42] was used to convert DBH $(D)$ and wood density $(\rho)$ 
values to AGB according to an environmental stress factor $(E)$ that averaged -0.096 across the plots. The form of the equation is as follows:

$$
\mathrm{AGB}=\exp \left[-1.803-0.976(E-\ln (\rho))+2.673 \ln (D)-0.0299 \times[\ln (D)]^{2}\right]
$$

The AGB was adjusted to account for structural damage where this was recorded in the census, and fallen stems were assigned an AGB of zero. The application of this allometry constitutes the main source of error in field based estimates of AGB, as tree-level values have a relative error of around 50\% [42]. Furthermore, it has been found that large trees $(\mathrm{DBH}>70 \mathrm{~cm})$ are poorly characterised by this allometry [43], in part due to the lack of destructive harvest data from large trees, and also due to the large variation in AGB of such trees $[44,45]$. This could have had a strong effect on our biomass change estimates, as only 2-7 trees were removed from each plot, and these had a median DBH of over $100 \mathrm{~cm}$. To avoid this, we used TLS to estimate the AGB of these trees with higher accuracy and less bias [46].

\subsubsection{Terrestrial Laser Scanning}

TLS surveys of all four selective logging plots were conducted in August 2019 using a Riegl VZ-400 scanner. For each plot, two scans were obtained at every point on a square $10 \mathrm{~m}$ grid aligned with the plot edges-one with the scanner orientated vertically and another with the scanner tilted horizontally to allow for complete (and oversampled) coverage of the hemisphere above each scan location. Highly reflective targets were used for approximate coregistration of the point clouds from successive scan positions, which was fine tuned using a plane-fitting algorithm implemented in Riegl's RiSCAN PRO software. The TLS acquisition followed the protocol of [47].

The point clouds of the logged trees were extracted from the coregistered data using an open-source software package called treeseg [48]. These were then used to create quantitative structural models (QSMs) according to the methods detailed in [49,50]. From the QSMs, the AGB of each tree was estimated by multiplying the model volume by wood density. The relative error in TLS derived AGB compared to destructive harvest values can be as low as 3\% [46], although older studies obtained 28\% [43], 23\% [51], and 16\% [50]. From this evidence, even in a worst case scenario TLS provides a considerable accuracy improvement compared to DBH-based allometry. Our final estimate of absolute AGB loss for each plot was given by the sum of the TLS-derived AGB of the logged trees plus the net change in AGB of the other trees as measured in the field survey.

\subsubsection{UAV Control Plots}

A canopy height change map covering 328 ha of forest around the selective logging plots was derived from UAV LiDAR data collected in January 2020 and January 2021. A RIEGL miniVUX-1DL discrete-return lidar was mounted to a DELAIR DT26X fixed-wing $\mathrm{UAV}$, which was flown at a height of about $140 \mathrm{~m}$ above the ground and at an average speed of $17 \mathrm{~m} / \mathrm{s}$. A GNSS base station was used for post-processing kinematic (PPK) corrections to the flight paths, which, in combination with ground control points, resulted in point clouds with a geometric accuracy of $1.8 \mathrm{~cm}$. The average point density was $240 \mathrm{pts}^{-2}$ [52].

Canopy height maps (CHMs) were derived at a pixel scale of $25 \mathrm{~cm}$ by taking the difference between the lowest and highest returns (after noise filtering) in each cell. The difference between the CHMs in 2020 and 2021 was taken to produce a $\triangle \mathrm{CHM}$ raster, and resampled to $2 \mathrm{~m}$ pixels. In 1 ha regions where fewer than $2 \%$ of $\triangle C H M$ pixels were less than $-5 \mathrm{~m}$, we randomly selected eleven control plots, as shown in Figure 2. The control plots are all square and orientated parallel to north. One control plot is situated on bare ground, while the rest are all in forested areas. 


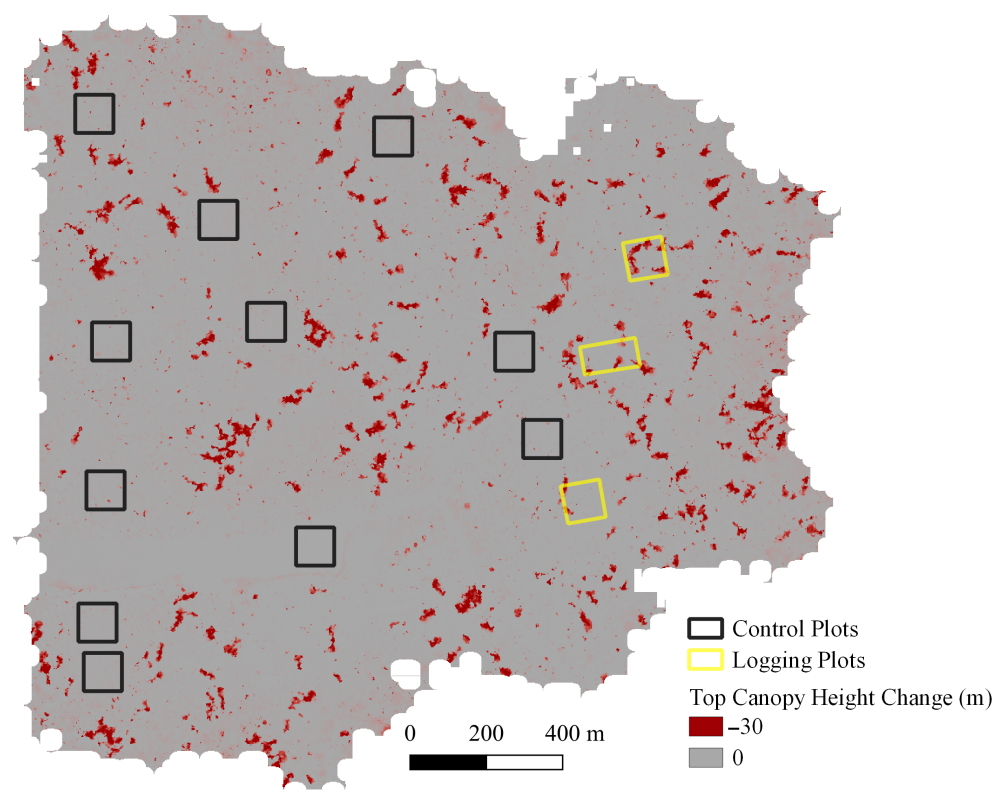

Figure 2. Top canopy height change from January 2020 to January 2021 measured using UAV LiDAR (background image), showing decreases in three logged plots (yellow rectangles) and no major changes inside our control plots (black squares). Note that most of the disturbances in the area occurred after the post-logging TDX acquisitions in February 2020.

\subsection{Topography of Field Site}

The region covered by TDX acquisitions has elevation varying from about 300 to $700 \mathrm{~m}$, while the area covered by UAV data ranges from 400 to $550 \mathrm{~m}$. These values are according to 1 arc-second SRTM data, which was also used to analyse slope steepness. As shown in Figure 3, a significant proportion of the area covered by the TDX acquisitions has slope $>10^{\circ}$, and the distribution of slopes in the region covered by UAV lidar is representative of this wider region.
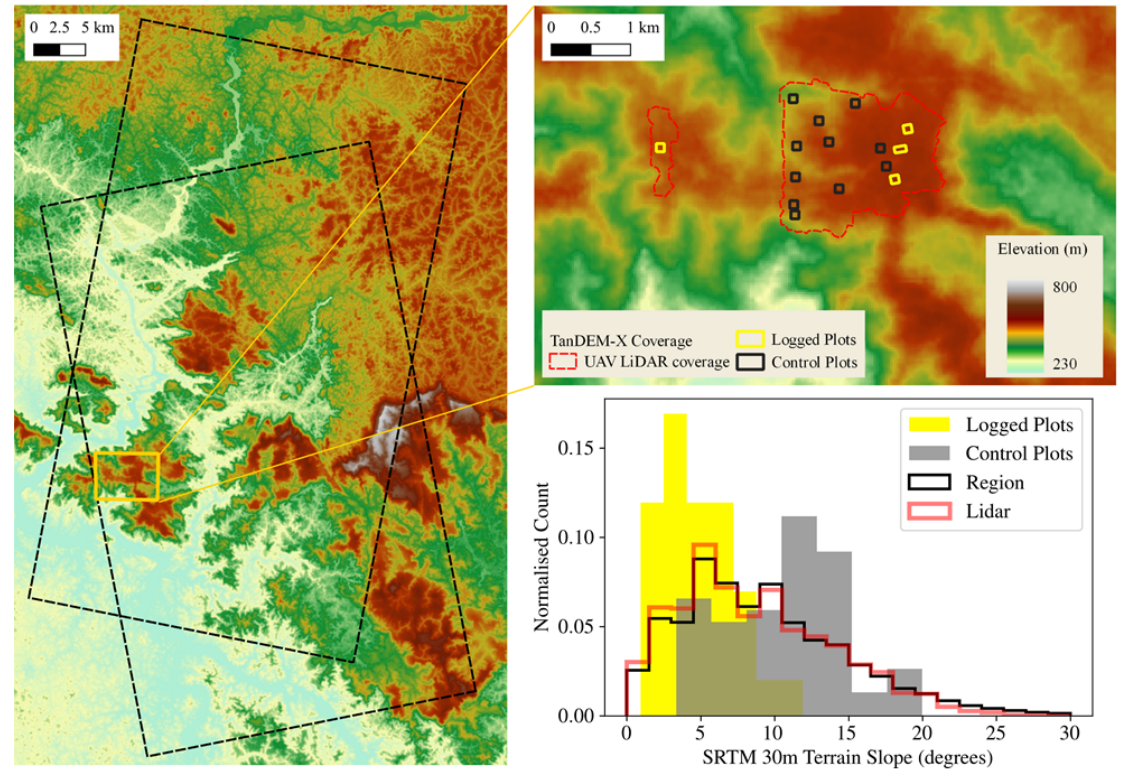

Figure 3. Elevation and slope statistics of the study site, according to 1 arc-second SRTM data. (Left) Elevation over the area covered by ascending and descending TDX acquisitions (dashed black rectangles). (Upper Right) Elevation over the area covered by UAV laser scanning (red dashed line) and containing our 1 ha plots (black and yellow rectanges). (Lower Right) Histograms of slope steepness for the TDX footprints, UAV Lidar coverage and field plots. 
The selective logging plots include a reasonable proportion of slopes between 5 and $10^{\circ}$, but are generally flatter than the surrounding topography (Figure 3 ). The control plots, meanwhile, contain steeper slopes typical of the region but no completely flat areas. This allowed us to build an empirical model relating TDX $h_{\phi}$ to $\triangle \mathrm{AGB}$ in flatter regions (where logging is more likely to occur anyway), while evaluating its stability in steeper regions using the control plots.

\subsection{InSAR Data Processing}

The Sentinels Application Platform (SNAP) software was used in conjunction with custom Python scripts to process the CoSSC images. All Python scripts written in conjunction with this paper can be accessed on Github at https:/ / github.com/harrycrstrs/tandex, accessed on 3 November 2021. The first step was to generate interferograms by multiplying the complex pixel values of the primary image by the corresponding conjugate values in the secondary image. This product has an argument equal to the phase difference between the images (the interferometric phase), which-ignoring decorrelation-is a function of the range difference from the target to the two satellites.

Two components of the interferometric phase were estimated and subtracted from the interferograms. The first of these was the theoretical phase that would be obtained from a featureless surface at zero elevation, known as the 'flat earth' phase. Secondly, the additional phase due to surface elevation was estimated using the 1 arc-second SRTM DEM [30]. By subtracting the SRTM phase, we obtained a residual component representing only the difference between SRTM and TDX $h_{\phi}$. This was beneficial because it reduced the range of phase values to less than $2 \pi$, as SRTM and TDX $h_{\phi}$ should not differ by more than the HoA [28]. As a result, the process of unwrapping to solve for absolute phase was considerably simplified. In summary, we calculated the phase difference between complex signals $A_{1} e^{\phi_{1}}$ and $A_{2} e^{\phi_{2}}$ and then subtracted the flat earth phase $\phi_{F E}$ and topographic phase $\phi_{S R T M}$ as follows:

$$
\phi=\arg \left(A_{1} A_{2} e^{i\left(\phi_{1}-\phi_{2}\right)}\right)-\phi_{F E}-\phi_{S R T M}
$$

Noise is present in $\phi$ over vegetated areas due to volume decorrelation [53], making it necessary to perform a multilooking step. In this study, we investigated the effect of multilooking on TDX sensitivity to forest disturbance by processing each interferogram with different numbers of looks, achieved by fixing the number of range looks between 3 and 32 and requiring an approximately square pixel in ground coordinates. This corresponded to pixel spacings ranging from $5.3 \mathrm{~m}(6.0 \mathrm{~m})$ to $53.4 \mathrm{~m}(66.5 \mathrm{~m})$ for the ascending (descending) passes. We will refer to results by the number of range looks $L_{R}$ as this was the fixed quantity in our processing chain.

Goldstein Phase Filtering [54] was applied to further reduce phase noise without reducing resolution. The adaptive filter exponent, which controls the strength of the filtering [55], was set to 0.2 (from a range of 0 to 1 ). This was kept low because we expected our interferograms to contain high phase gradients-for example around canopy gapswhich may have been smoothed over by strong filtering.

A basic unwrapping algorithm was then applied, under the assumption that no two 'true' phase values differed by more than $2 \pi$. This consisted of applying a constant offset $\delta$ according to Equation (3), where $i$ and $j$ refer to range and slant coordinates.

$$
\phi_{i j}^{u n w}= \begin{cases}\phi_{i j}+\delta, & \text { if } \phi<2 \pi-\delta \\ \phi_{i j}+\delta-2 \pi, & \text { otherwise }\end{cases}
$$

The optimal value for $\delta$ was estimated by numerically minimising the number of adjacent pixels that differed by more than five radians. This value is equivalent to a height difference of $43 \mathrm{~m}$ for the TDX acquisition with the smallest HoA, meaning anything beyond this could reasonably be assumed to be unphysical, considering the UAV data showed trees higher than this to be uncommon. 
At this stage, most images contained a systematic phase component dependant on range and azimuth coordinates. This 'ramp' is likely due to small errors in orbit information [26], but can be corrected using standard methods. A random sample of 10,000 points was taken from each image and fitted by least squares to a plane. The plane was then subtracted from the unwrapped phases to give deramped phases according to the Equation (4), where $\alpha, \beta$ and $\gamma$ are the parameters of the plane.

$$
\phi_{i j}^{\text {deramped }}=\phi_{i j}^{u n w}-\alpha i-\beta j-\gamma
$$

The unwrapped, deramped phase values were converted to $h_{\phi}$ by dividing them by the interferometric wavenumber $k$. This was calculated on a pixel-by-pixel basis from slant range $R_{i j}$ and incidence angle $\Theta_{i j}$, according to Equation (5), where $B_{\text {eff }}$ is the effective perpendicular baseline [56].

$$
k_{i j}=\frac{4 \pi B_{e f f}}{R_{i j} \lambda \sin \left(\Theta_{i j}\right)}
$$

Finally, the SNAP tool for range-doppler terrain correction was applied using the SRTM 1 arc-second DEM, thus transforming the images into geographic coordinates.

\subsection{Multilooking}

A quantitative analysis in [26] shows that TDX $h_{\phi}$ is typically located within $1 \mathrm{~m}$ of the mean height of the $X$-band radar scattering profile. In the case of a tropical forest, we can relate this to the spatial distribution and sizes of leaves and branches-the higher these scattering surfaces are, the higher $h_{\phi}$ will be. Under the assumption of stable topography, we can therefore relate changes in successive measurements $\Delta h_{\phi}$ to changes in vegetation structure. Specifically, we hypothesised that plots with the highest intensity logging and greatest losses of AGB would show the largest reductions in $h_{\phi}$.

However, changes at the pixel level will occur for a number of reasons, including variations in sensor geometry and movement of scatterers in the canopy. For this reason, it seems desirable to use a large number of multilooks in order to average out these variations. Previous studies examined phase changes at a scale of $50 \mathrm{~m} \mathrm{[26,27].} \mathrm{On} \mathrm{the}$ other hand, it is important to recognise that variations in $h_{\phi}$ are related to the vertical structure of tropical forest, rather than being simply 'noise', meaning that spatial averaging risks the loss of useful information [57]. The X-band signal is able to penetrate through small gaps, resulting in a few-look $h_{\phi}$ distribution that correlates strongly with forest height [28]. Our first analysis, therefore, was to compare relationships between $\Delta h_{\phi}$ and $\triangle$ AGB from selective logging at different levels of multilooking, to determine the optimal level for quantification of biomass change. It should be noted here that by multilooking, we specifically refer to spatial averaging of the complex radar signal, as opposed to spatial averaging of $h_{\phi}$, which was performed in all cases.

We estimated $h_{\phi}$ changes in the logged plots according to Equation (6), where $\overline{h_{\phi}^{\text {pre }}}$ and $\overline{h_{\phi}^{\text {post }}}$ indicate the mean of pre- and post-logging images, respectively. The sum was taken over all pixels intersecting with a $10 \mathrm{~m}$ buffer around the plots, to allow for the fact that some logged trees fell outside of the plot boundaries.

$$
\Delta h_{\phi}^{\text {plot }}=\sum_{\text {plot }}\left(\overline{h_{\phi}^{\text {post }}}-\overline{h_{\phi}^{\text {pre }}}\right)
$$

To ensure spatial averaging was performed over the same area at each level of multilooking, all images were resampled using the nearest neighbour method to the coordinates of the first $3 \times 3$ look ascending image. Although each $h_{\phi}$ layer contained an arbitrary constant, no calibration was required because our analysis was concerned only with the spatial variation in $\Delta h_{\phi}$. Instead, the resulting constant term in $\Delta h_{\phi}$ was approximated by 
assuming the average change over the image was zero. For this part of the analysis, all acquisitions from both pass directions were used.

\subsection{Combining Pass Directions}

In hilly terrain, it is inevitable that some slopes will face towards the SAR sensor, resulting in small local incidence angles $\theta_{i}$. This degrades the range resolution on the ground and leads to poor coherence [58-60], as reflections from across such slopes are compressed in the slant range direction, as illustrated in Figure $4 \mathrm{a}, \mathrm{b}$.

(a)

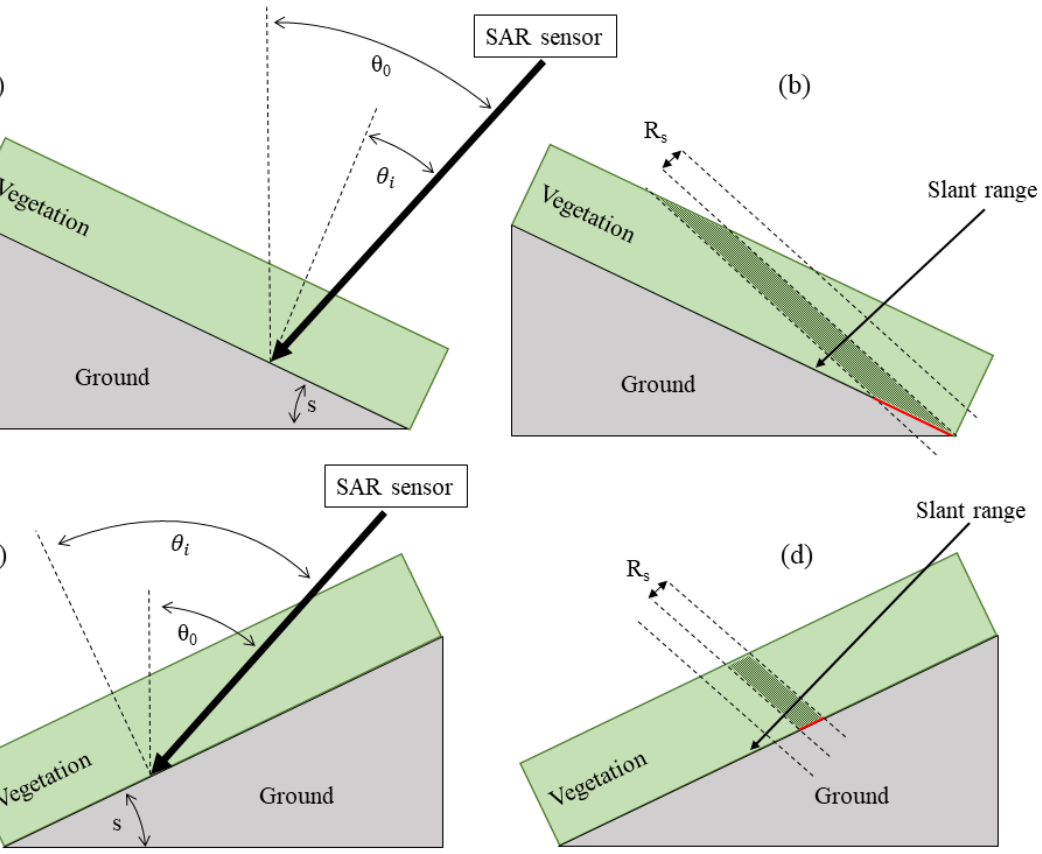

Figure 4. Effect of steep slopes on InSAR signal. (a) Where slopes face towards the sensor, the local incidence angle $\theta_{i}$ becomes small. (b) Considering the range resolution of the sensor $R_{S}$, each resolution cell contains an excessive volume of vegetation and an extended area of ground, leading to poor angular coherence in the scattered signal. The opposite case is shown in (c) where the slope faces away from the sensor, leading to large $\theta_{i}$. (d) For the same $R_{S}$, fewer scattering components are present in each resolution cell.

In contrast, slopes facing away from the SAR sensor with large values of $\theta_{i}$ lead to smaller areas of ground and less vegetation in each range bin, as shown in Figure $4 \mathrm{c}, \mathrm{d}$. Small values of $\theta_{i}$ can be suppressed by fusing data from multiple pass directions: a technique previously shown to improve DEM creation and water body detection using TDX data [61]. To quantify this, we consider how $\theta_{i}$ relates to viewing geometry and topography. Specifically, it may be expressed in terms of terrain slope from horizontal $S$, slope aspect from north $a$, sensor azimuth angle from north $z$ and radar incidence angle to the vertical $\theta_{0}$.

$$
\theta_{i}=\theta_{0}+S \cos (a-z)
$$

An illustration of $\theta_{i}(a)$ for fixed $S$ is shown in Figure 5a. By the nature of a sunsynchronous orbit (such as the one used by TDX) the azimuth angles for ascending $\left(z^{A}\right)$ and descending $\left(z^{D}\right)$ passes are fixed for a given scene. Slope aspect, on the other hand, may be anything between 0 and $360^{\circ}$. Therefore, for a given $S$, we can write the lower bound of $\theta_{i}$ for each pass.

$$
\operatorname{argmin}\left[\theta_{i}(a)\right]=\left\{\begin{array}{lll}
\theta_{0}^{A}-S, \text { when } & a=-z^{A} & \text { for ascending passes } \\
\theta_{0}^{D}-S, \text { when } & a=-z^{D} & \text { for descending passes }
\end{array}\right.
$$


If we allow the possibility of flexibly choosing either pass for a given slope and aspect, then the minimum value of $\theta_{i}$ can be increased if the ascending and descending curves cross, that is, if there is a value of $a$ which satisfies:

$$
\theta_{0}^{A}+S \cos \left(a-z^{A}\right)=\theta_{0}^{D}+S \cos \left(a-z^{D}\right)
$$

This equation has a solution when the following condition is met:

$$
S \geq \frac{\left|\theta_{0}^{D}-\theta_{0}^{A}\right|}{2}
$$

In other words, selecting from multiple pass directions mitigates small $\theta_{i}$ for slopes greater than a critical angle, equal to half the difference between the ascending and descending nominal incidence angles. Below this threshold, one pass always has higher $\theta_{i}$ than the other. Intuitively, the magnitude by which $\theta_{i}$ is enhanced will be greatest when $z^{A}-z^{D}=180^{\circ}$, that is, when the cosine terms in Equation (7) for the two passes are perfectly out of phase. In this situation, slopes that face towards the sensor during one pass face away from it during the opposite pass. As sun-synchronous orbits are nearly polar, the reality is not too far away from this ideal condition-for our TDX scenes $z^{A}-z^{D}=157.4^{\circ}$. While Equation (9) has no analytical solution, a numerical result is shown in Figure 5b, confirming that $\theta_{i}$ enhancement is strongest for the steepest slopes.
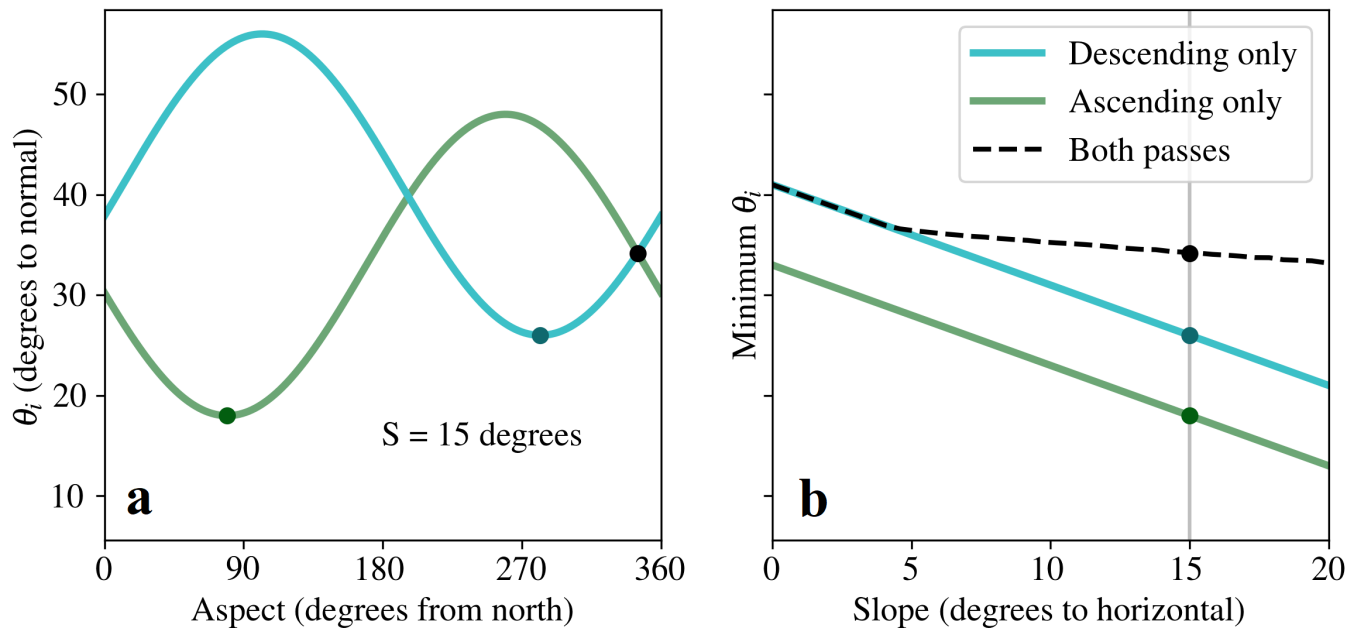

Figure 5. Analysis of local incidence angle $\theta_{i}$ as a function of pass direction, slope (S) and aspect, as given by Equation (7). For our TDX scene, $z^{A}=79.4^{\circ}$ and $z^{D}=282.0^{\circ}$. (a) For a given steepness of slope, $\theta_{i}$ varies with the cosine of aspect. As $z^{A}-z^{D}$ is close to $180^{\circ}$, the curves for the two pass directions are highly out of phase. (b) The minimum possible $\theta_{i}$ is shown as a function of terrain slope for each pass, and for the case where pass is chosen flexibly. The dots highlight the corresponding points between the two graphs, which share the same y-axis.

To test if pass selection provides more stable results in practice, we estimated degradation across the AOI using four different methods. The first two methods used one acquisition of each pass direction from before and after the selective logging event. For the naive averaging method, the change in $h_{\phi}$ for each pixel was calculated using data from both pass directions according to:

$$
\Delta h_{\phi}=0.5 \times \sum_{A, D}\left(h_{\phi}^{\text {post }}-h_{\phi}^{\text {pre }}\right)
$$

where the sum is over ascending and descending passes. In contrast, the pass selection method used the estimated projected local incidence angle (based on SRTM data) $\theta_{i}$ and 
median coherence values for each pass $\gamma$ to determine which pass direction to use for each pixel, according to the algorithm shown in Equation (12).

$$
\Delta h_{\phi}= \begin{cases}{\left[h_{\phi}^{\text {post }}-h_{\phi}^{\text {pre }}\right]^{A},} & \text { if } \theta_{i}^{A}>20^{\circ}+\theta_{i}^{D} \\ {\left[h_{\phi}^{\text {post }}-h_{\phi}^{\text {pre }}\right]^{D},} & \text { or }\left(\left|\theta_{i}^{D}-\theta_{i}^{A}\right| \leq 20 \text { and } \gamma^{A}>\gamma^{D}\right)\end{cases}
$$

The coherence was used for flatter areas as topographic features $<30 \mathrm{~m}$ in size may not be well represented in the SRTM data, and because other factors (such as range bandwidth) also have an effect on image quality. Areas that had low coherence in both pass directions $(\gamma<0.4)$ were masked. In addition, an ascending only estimate was obtained using all four ascending acquisitions, and a descending only estimate was obtained using all four descending acquisitions. For these estimates, pixels for which $\gamma<0.4$ were masked, and $\Delta h_{\phi}$ was simply taken as $\overline{h_{\phi}^{\text {post }}}-\overline{h_{\phi}^{\text {pre }}}$.

For each method, $\Delta h_{\phi}$ was averaged to a pixel size of 1 ha. Then, a linear modelthe parameters of which were determined by comparison to our field data-was used to produce estimates of $\triangle \mathrm{AGB}$.

\section{Results}

\subsection{Field Measured Biomass Change}

Of all measured stems in the four selectively logged plots, wood density was estimated at the species level for $42 \%$ and at the genus level for $27 \%$. The remaining $31 \%$ were assigned the average wood density of the other stems within that plot. For the logged trees, TLS modeling and allometry gave broadly similar estimates of AGB. The mean absolute difference between the two methods at the tree level was $2.4 \mathrm{Mg}$, and overall allometry estimated 6\% less AGB in all 18 trees compared to TLS.

The initial AGB in the four selectively logged plots varied from 400 to $570 \mathrm{Mg} \mathrm{ha}^{-1}$. The losses incurred due to logging ranged from 28 to $131 \mathrm{Mg}$, representing percentage losses of $7 \%$ to $23 \%$, as shown in Table 2 . The lower end of this scale (plots 2 and 3 ) was proportionate to losses that might be expected from naturally occurring tree mortality. Meanwhile, the higher intensity logging that occurred in plots 1 and 4 was representative of a significant disturbance such as targeted logging and timber extraction.

Table 2. Aboveground biomass (AGB) and AGB loss of four 1 ha selectively logged plots, measured by field inventory and terrestrial laser scanning (TLS).

\begin{tabular}{ccccc}
\hline Plot & Pre-Logging AGB (Mg ha $\left.{ }^{-1}\right)$ & Trees logged & $\Delta$ AGB $\mathbf{( M g )}$ & $\Delta$ AGB (\%) \\
\hline 1 & $570 \pm 40$ & 7 & $131 \pm 13$ & $23 \pm 3$ \\
2 & $400 \pm 30$ & 2 & $28 \pm 5$ & $7.1 \pm 1.3$ \\
3 & $440 \pm 30$ & 4 & $55 \pm 7$ & $12.6 \pm 1.8$ \\
4 & $470 \pm 40$ & 5 & $109 \pm 10$ & $23 \pm 3$ \\
\hline
\end{tabular}

\subsection{Effect of Multilooking Parameters on Biomass Change Estimation}

Our analysis found that minimising the level of multilooking $\left(L_{R}=3\right)$ provided the strongest relationship between $\Delta h_{\phi}$ and $\triangle$ AGB. We determined this by fitting linear models to the plot averaged $\Delta h_{\phi}$ and the AGB losses reported in Table 2. The sensitivity to $\triangle A G B$ was then defined simply as the linear coefficient in the model, that is, the drop in $h_{\phi}$ expected per Mg of AGB loss. As shown in Figure 6, this value was $2.3 \mathrm{~cm}$ per $\mathrm{Mg}$ when using $L_{R}=3$, and generally decreased with increasing $L_{R}$. The correlation coefficient for the $L_{R}=3$ linear model was 0.996 - greater than the value for any other level of multilooking, thus we are confident that our result is the product of a robust trend and not chance. 
In addition, variability in the control plots where no logging took place was minimised by the same level of multilooking. Figure 6 shows that the control plot standard deviation of $\Delta h_{\phi}$ was 0.66 for $L_{R}=3$ and steadily increased with increasing $L_{R}$. This shows that in addition to being more sensitive to AGB losses, fewer-look interferograms were more stable at the 1 ha level for regions where no changes occurred.

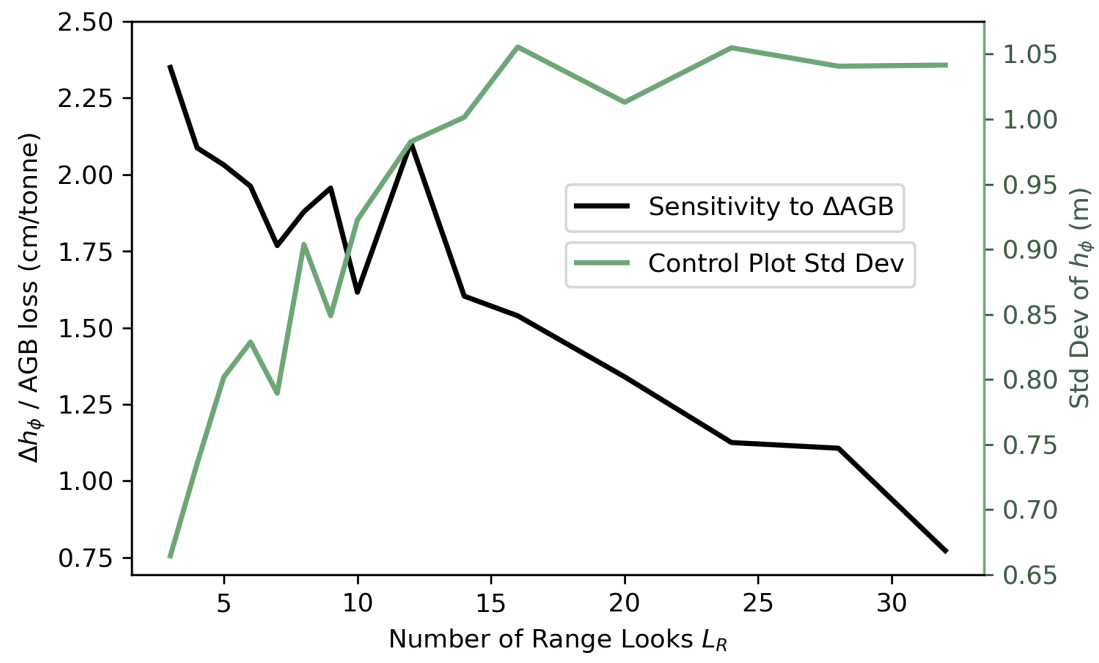

Figure 6. (black, left hand y-axis) Modeled drop in phase height $\left(h_{\phi}\right)$ in cm per Mg of AGB loss, calculated for various levels of multilooking. (green, right hand y-axis) Standard deviation of $\Delta h_{\phi}$ for the 11 control plots, plotted against multilooking level.

It should be noted that we do not attempt here to justify the use of a linear model over more complex forms through any theoretical means. All four plots were located in the same region and had fairly similar structures and canopy heights, meaning that it would not have been meaningful to attempt a model including other forest variables in this case. With this in mind, our results do show a strong linear trend. We demonstrate this for the case of $L_{R}=3$ in Figure $7 \mathrm{a}$, which shows the line of best fit and uncertainties associated with $\triangle \mathrm{AGB}$ and $\Delta h_{\phi}$ (we estimated uncertainties in $\Delta h_{\phi}$ using the coherence and the Cramer-Rao bound [18]). For comparison, Figure 7b shows the case of $L_{R}=32$, for which the linear trend is still plausible, but significantly weaker.
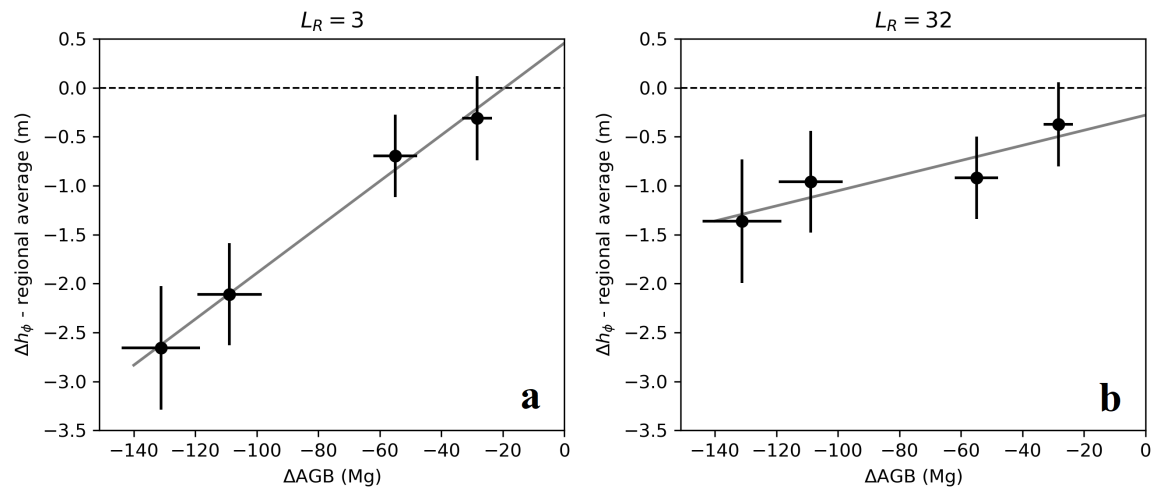

Figure 7. Relative $h_{\phi}$ change between pre-logging and post-logging TDX acquisitions for the four 1 ha logging plots, plotted against field measured $\triangle \mathrm{AGB}$. Multilooking was set to $3 \times 3$ (a) and $32 \times 32$ (b) Linear fits are shown in grey.

\subsection{Effect of Terrain on Coherence}

Terrain aspect, slope, and bandwidth were found to be strong drivers of interferometric coherence. We assessed this using SRTM data at $30 \mathrm{~m}$ resolution and TDX interferograms 
of opposite pass directions multi-looked to a pixel size of $30 \mathrm{~m}$. In agreement with the theory presented in Section 2.7, the results showed that where slopes faced away from the sensor, coherence was generally good, even for steep slopes (up to around $25^{\circ}$ ). On the other hand, coherence rapidly deteriorated with slope steepness for aspects facing towards the sensor. However, as the azimuth angles of ascending and descending passes differed by $157^{\circ}$, almost all terrain had good coherence for one of the pass directions. This is illustrated in Figure 8, which also shows that ascending pass had higher coherence overall, likely due to its larger radar bandwidth and despite the smaller nominal incidence angle.

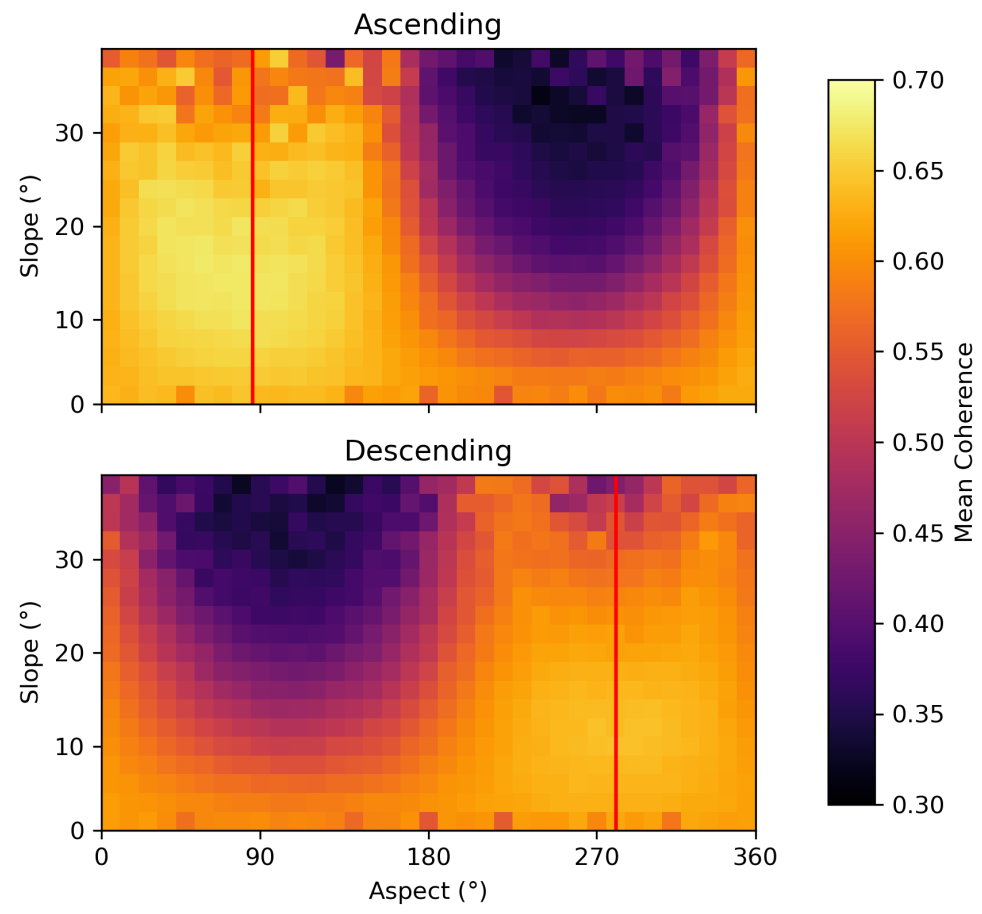

Figure 8. Heat map of average coherence for $30 \mathrm{~m}$ TDX pixels binned by SRTM slope steepness and aspect for an ascending pass and a descending pass. Red lines indicate the azimuth direction for each pass, which represents the aspect at which slopes face away from the sensor.

\subsection{Importance of Multiple SAR Geometries for Noise Reduction}

Overall we found the pass selection method to be highly successful in removing any relationship between observed $\Delta h_{\phi}$ and local incidence angle. In the overlapping region between the TDX passes, pass selection produced values of $\Delta h_{\phi}$ that were effectively not biased by topography at all, with no change in $\Delta h_{\phi}$ (Figure 9a) or its standard deviation (Figure $9 b$ ) as $\theta_{i}^{A}$ varies. This is in contrast to the case where both pass directions are averaged; using this method, regions of strong slopes showed large decreases in $h_{\phi}$ and large variability.

Selecting pass direction on a pixel-by-pixel basis also led to improved stability of $\Delta h_{\phi}$ in our control plots (see Table 3). The standard deviation of $\Delta h_{\phi}$ amongst those eleven plots where no logging took place was smallest $(0.46 \mathrm{~m})$ when using the pass selection method and largest $(0.60 \mathrm{~m}$ for ascending and $0.83 \mathrm{~m}$ for descending) when using only a single-pass direction. We stress here that we used the same number of TDX images for each method, so this result cannot be attributed to simply an increase in data input.

At a scale of $1 \mathrm{ha}$, the pass selection method produces a more plausible map of predicted biomass loss. A comparison of this potential degradation map to the naive averaging method is given in Figure 10. It is clear that naive averaging results in a gross over-estimate of biomass loss: $5 \%$ of the 1 ha pixels in this map report a reduction in AGB of over $100 \mathrm{Mg}$. This magnitude of loss would indicate widespread tree felling across the 
entire study area, which is extremely unlikely given the short time span and the fact that much of the region is outside of the logging concession and within a national park.
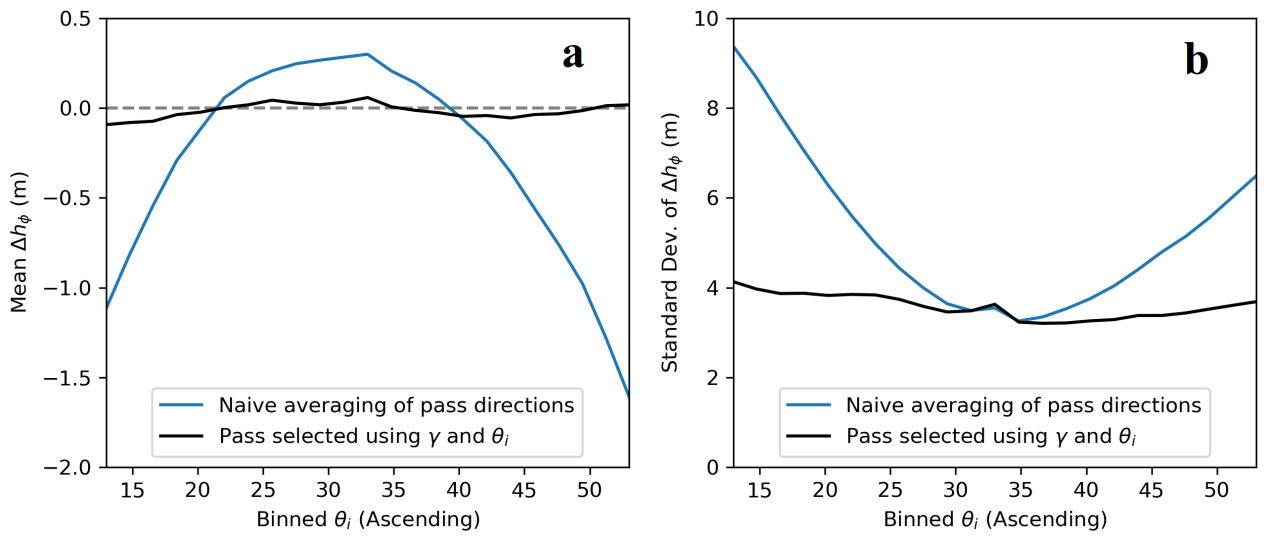

Figure 9. Statistics of $\Delta h_{\phi}$ at the $(3 \times 3$ multi-looked) TDX pixel level, binned by estimated local incidence angle for the ascending pass, which is essentially a proxy for terrain slope. Results obtained by averaging data from different pass directions (blue) is compared to results obtained by selecting pass direction at the pixel level (black). (a) Pass selection mitigates bias in the mean, and (b) reduces variance.
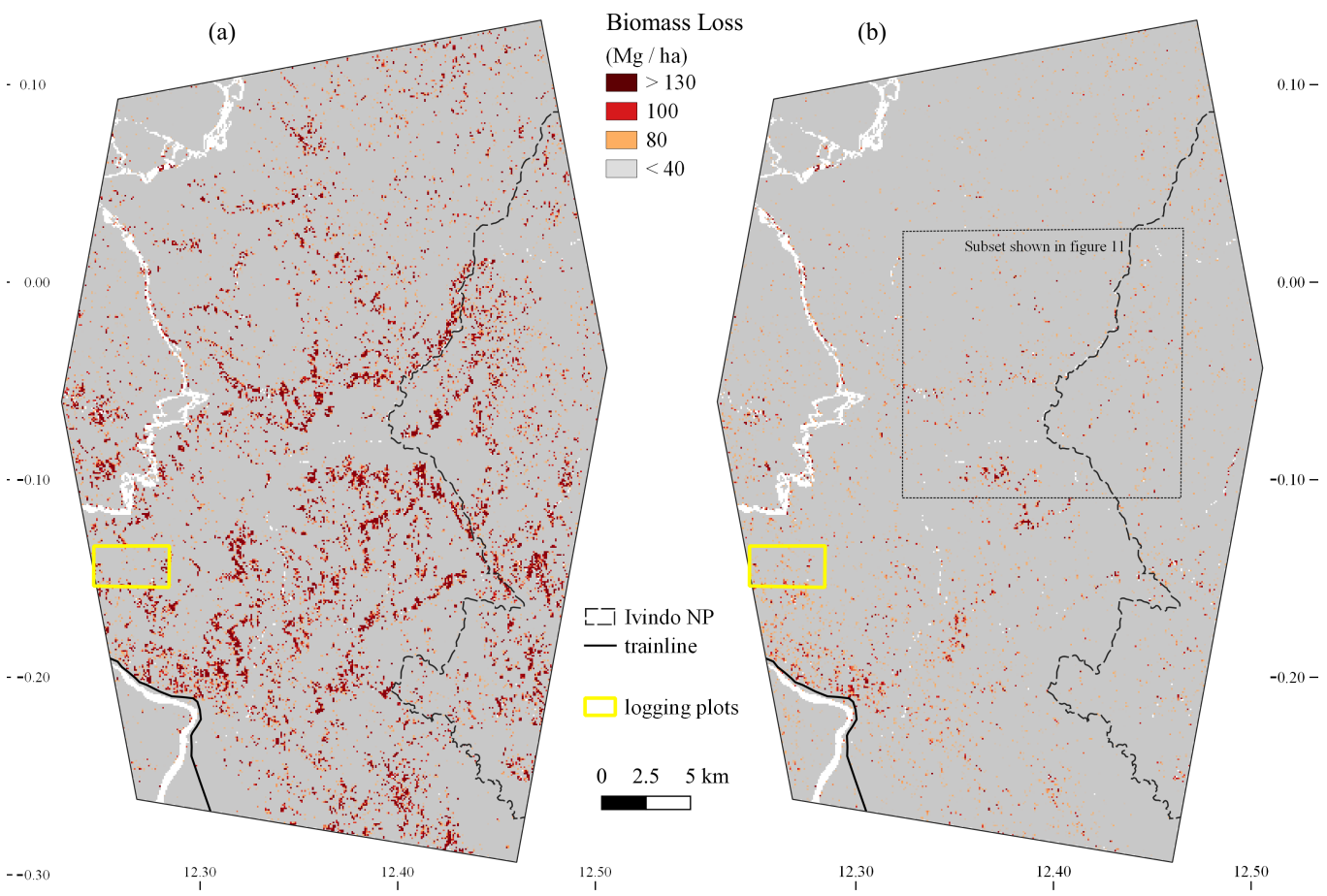

Figure 10. Maps of potential forest degradation based on TDX $h_{\phi}$ change, ranging from grey (no detectable AGB loss) to dark red (>130 Mg AGB loss per ha). (a) Averaging changes across both pass directions led to a severe over-estimation of degradation. (b) Selecting pass at the pixel level mitigated topographic artifacts: the method we recommend here. 
Table 3. Stability of $\Delta h_{\phi}$ in eleven control plots where no logging took place, by the four methods described in Section 2.7.

\begin{tabular}{cc}
\hline Method & Standard Deviation of $\Delta \boldsymbol{h}_{\boldsymbol{\phi}}(\mathrm{m})$-Control Plots \\
\hline Pass selection & 0.46 \\
Naive averaging of passes & 0.52 \\
Ascending passes only & 0.60 \\
Descending passes only & 0.83 \\
\hline
\end{tabular}

\section{Discussion}

We found that the selection of the optimal TDX pass direction for each pixel removes the sensitivity of interferometric phase height change $\left(\Delta h_{\phi}\right)$ to incidence angle $\left(\theta_{i}\right)$. In our case, with images spanning about a month, this led to a plausible map of forest degradation over a study area. The measured $\Delta h_{\phi}$ responded well to the magnitude of change in our field plots, but whether this holds for areas of higher slopes remains currently unvalidated with field data; however, it appears plausible. This suggests that, even in hilly areas, X-band InSAR appears to be a useful method for quantitatively mapping the presence and magnitude of biomass change, provided images are captured from ascending and descending passes. With one pass only, errors on slopes facing the sensor are large, and likely impossible to correct in post-processing.

Unlike the majority of current methods for large-scale degradation mapping, which output binary results [62], our InSAR approach provides a measure of the magnitude of biomass change (Figure 7). There is a need for measurements of this kind because countries are required by the Intergovernmental Panel on Climate Change to report the biomass extracted during commercial felling as an immediate carbon emission [63], regardless of how the timber is subsequently used. A binary indicator of degradation could mask differences in emissions intensity spanning an entire order of magnitude, and such differences are not random: they are driven by the type and intensity of degradation, for example the number of logged trees and reduced impact logging practices. This means that spatial averaging will not be sufficient to estimate carbon losses based on a binary map of degradation. Such maps would therefore force policy makers to assume that regions undergoing the most degradation by area are the most at risk, despite the fact that these regions could be experiencing lower levels of biomass depletion than other regions with localised but more intense degradation. While lidar surveys by UAV or plane can provide more accurate quantitative measures of forest structural change, it is not feasible to make regular surveys spanning the whole of the tropics with these platforms. Spaceborne InSAR, therefore, appears to be a promising approach to fully quantifying carbon emissions from forest degradation.

An additional advantage to our approach is that it can detect changes in humid tropical forests throughout wet and cloudy seasons, during which cloud-free optical imagery is rare. Especially in central Africa and SE Asia, where cloud cover is high all year round, this is vital to producing accurate degradation maps. Relying on optical data could-at best-lead to lag times of a year or more before degradation is detected, and at worst, could result in degradation in cloudy regions being missed entirely.

Our study highlights the uniquely rich data of TDX. It is important, however, to note some limitations of this sensor. The main objective of the TDX mission is to create a worldwide DEM, and as such, its acquisition program is not optimised for tropical forest monitoring. Acquisitions for science applications cannot be requested for particular dates, as they must be taken in the gaps between the systematic DEM acquisitions, meaning that regular repeat times are not guaranteed [64]. While TDX has already surpassed its design lifetime, it is predicted to continue performing well for several more years [64], potentially providing more opportunities during the 2020s for experimental acquisitions. A number of new X-band SAR constellations are now being developed commercially (such as Umbra, ICEEYE and Capella Space), but we are not aware of any that will attempt to replicate the 
bistatic formation of TDX required for coherent interferometry of forests. It may be crucial, then, to make use of this novel imaging mode for scientific purposes while it is available.

\subsection{Importance of Multiple Geometries in SAR Acquisition}

Our results show that collecting SAR imagery from both ascending and descending passes leads to a transformational improvement in the quality of interferometric data over tropical forests, even in areas of moderate topography. This improvement comes about directly from the multiple viewing geometries (because slopes greater than $10^{\circ}$ lead to poor coherence when facing away from the sensor) and is not related to the overall volume of data. If anything, our results suggest that fewer acquisitions with multiple geometries would be far more useful for this application than a dense time series where every image is from the same pass direction.

This finding adds to the list of applications where multiple geometries are known to be beneficial. This includes the use of S-1 SAR shadows to detect patches of tropical deforestation [20]. Furthermore, Du et al. showed that multiple geometries also leads to improved accuracy in detecting waterbodies with TDX data, as well as creating DEMs in complex terrain, including urban environments [61]. Multiple passes are also important when using InSAR to precisely track targets in 3D, such as ice flows [65], artificial reflectors [66], or geological faults [67].

Despite this, multiple geometries are not always prioritised by spaceborne SAR acquisition plans. In the case of TDX, a second global DEM is currently being produced, but this relies on a single acquisition for "considerable areas", meaning that many changes in these regions could be masked by topography [68]. Furthermore, the S-1 mission only ever collects one pass direction for vast swathes of the Brazilian Amazon and central Africa [69]. Although bistatic interferometry is not possible with S-1, this still raises the concern that change detection in tropical forests could be adversely affected. To ensure total coverage, future SAR missions should aim to pass over all areas of interest in both directions.

\subsection{Importance of Few-Look Interferograms}

A strong relationship between TDX $h_{\phi}$ and AGB change was obtained by using fewlook interferograms. It should be stressed that we still averaged values of $\Delta h_{\phi}$ to a 1 ha pixel size to generate maps of degradation: our finding is that performing this averaging on the real valued $h_{\phi}$ pixels was more effective than averaging the complex valued SAR signal. This suggests that the distribution of single look phases contains valuable information relating to the distribution of scatterers in dense vegetation, and should not be thought of as "noise" to be smoothed out.

The minimum number of looks we tested was $3 \times 3$, and this gave us the best sensitivity of $\Delta h_{\phi}$ to $\triangle \mathrm{AGB}$. It may be possible to attempt an analysis using even fewer looks or no multilooking at all, but the computational requirements may become disproportionately large. On the other hand, it may be that different levels of multilooking can provide complementary information. Future work could investigate this by using multiple layers to take into account changes across different scales.

Our finding is in agreement with a previous study that used few-look TDX interferograms to estimate forest height [28]. This was achieved by approximating the ground phase as $\mu-2 \sigma$, where $\mu$ was the mean and $\sigma$ the standard deviation of phase values over an area of 1 ha. Our results show that few-look interferograms are useful not just for estimating the ground elevation, but also for detecting structural changes throughout the vegetation profile.

\subsection{Evaluation of Predicted Biomass Loss Maps}

In addition to demonstrating the importance of multiple pass directions and few-look interferograms, we also extrapolated our method to the area of 115,370 ha over which the ascending and descending TDX passes overlapped. A cluster of severe biomass loss is discernible in the predicted map (Figure 10b) around $(12.4,-0.1)$. We are aware that 
logging operations were happening outside of the controlled plots at the time of the TDX acquisitions, in a limited geographical area to their north and east. While the cluster of loss may correspond to those logging operations, no data on their precise location has been published yet. Outside of this cluster, the map mostly indicates a random distribution of small disturbances which could realistically occur naturally as larger trees die, as well as a concentration of degradation in close proximity to the section of railway line leading to Ivindo village, where additional human disturbances might be expected due to accessibility.

Some topographic effects do still persist when using the pass selection method, although they are less pronounced than when using the naive method (Figure 10a). These residual effects are illustrated in Figure 11, where spatial patterns of biomass loss match regions of steep topography. Additional artifacts are present where changing water levels may have exposed islands in the wide rocky rivers, but it is possible to mitigate these using a forest/non-forest mask.
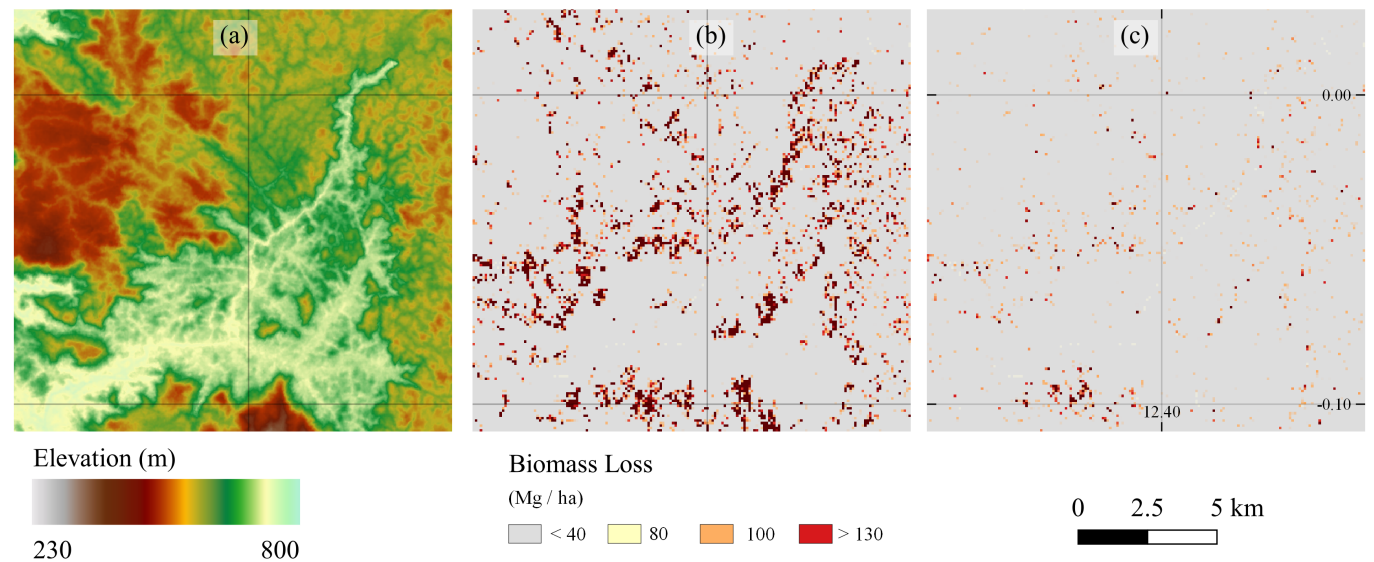

Figure 11. Example of topographic artifacts in TDX predicted degradation. (a) SRTM elevation; (b) potential degradation using naive averaging method; (c) potential degradation using pass selection method.

\subsection{Comparison to Other Forest Disturbance Products}

Here we make a brief comparison of our results to the RAdar for Detecting Deforestation (RADD) disturbance alerts [19]. This product maps and estimates the date of disturbances greater than 0.2 ha in size by detecting changes in S-1 backscatter [19]. Although S-1 has a lower resolution than TDX at around $20 \mathrm{~m}$ [70], it provides the advantage of regular repeat passes (every 12 days over our study area) which allow long time series to be analysed. S-1 data is also publicly available and has global coverage, giving it huge potential for large-scale forest monitoring.

We compared RADD disturbance alerts from January 2020 onwards to our TDX derived estimates of degradation, using $3 \times 3$ looks and the pass selection method. In the cluster of degradation visible around the centre of our TDX scene which may be associated with logging activity, we found disturbances that were a spatial match across both data sets (see, for example, Figure 12).

Overall, $11.6 \%$ of RADD alerts in the first half of 2020 coincided with areas where TDX $\Delta h_{\phi}$ was less than $-1.5 \mathrm{~m}$, compared to a baseline of $1.5 \%$ across the study area, further suggesting some crossover in the events being detected by the two approaches. We included a time period extending beyond our final TDX acquisition to account for the fact that the statistical method used to generate RADD alerts may lead to late detections [19]. On the other hand, the remaining $88.4 \%$ of TDX degraded area was not captured in the RADD alerts. This is likely to be due in part to the ability of TDX to pick up disturbances smaller than the 0.2 ha minimum mapping unit in the RADD product, which was comparatively insensitive to low level degradation. We found the RADD product was most sensitive to degradation events that caused TDX $h_{\phi}$ to decrease by around $2 \mathrm{~m}$ or more, as shown 
in Figure 13. Although $\Delta h_{\phi}$ exceeded this $2 \mathrm{~m}$ threshold for two of our measured plots, the RADD alerts did not detect those events, suggesting that selective logging events of this kind are not spatially continuous enough to present as a disturbance greater than 0.2 ha, despite the fact that more than five large trees were removed from each hectare of forest.

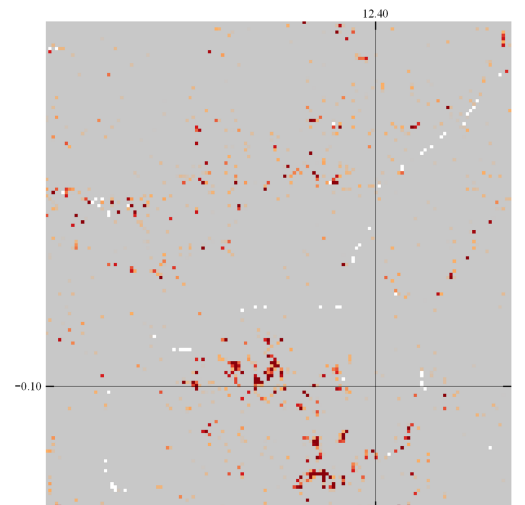

(a)

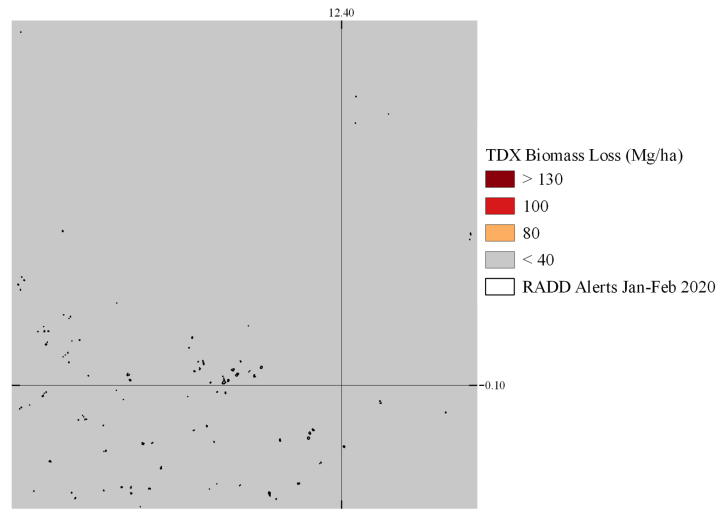

(b)

Figure 12. (a) Predicted biomass loss from TDX data using the pass selection method (same as Figure 11c). (b) Radar for detecting deforestation (RADD) forest disturbance alerts from January and February 2020 over the same area.

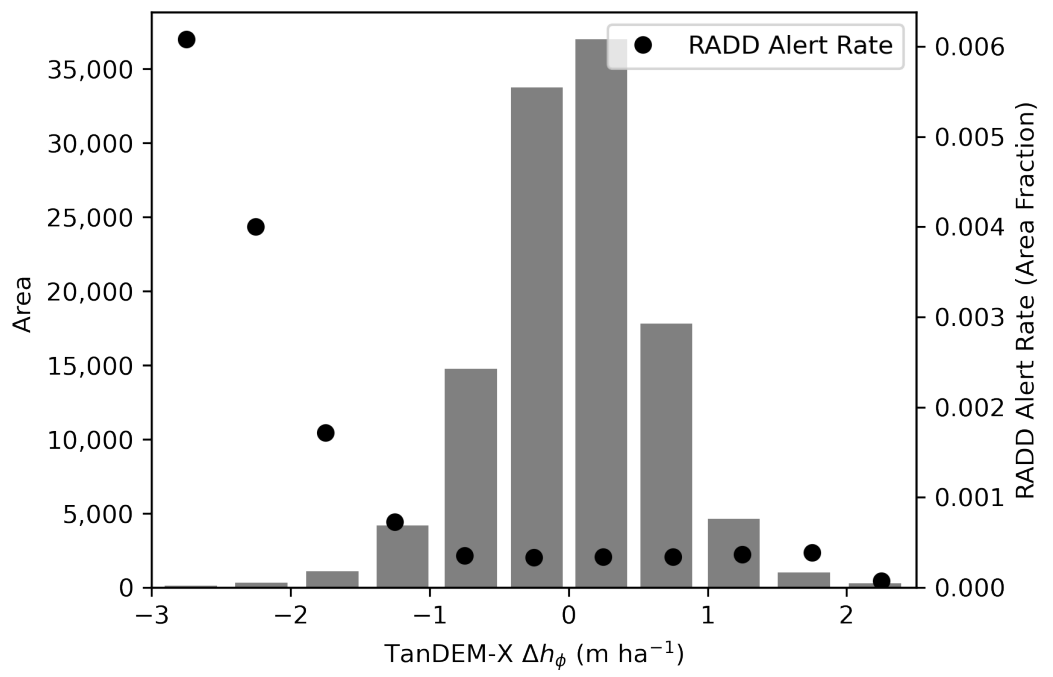

Figure 13. RADD forest disturbance alert rate (area of alerts in the first half of 2020 divided by total area) is shown as black dots, binned by magnitude of TDX $h_{\phi}$ change. The total area in each bin is indicated by the bar chart. Alert levels increase with the magnitude of degradation predicted by TDX.

In addition, our biomass loss map is likely to contain commission errors due to phase noise and topographic effects. Unfortunately, quantifying the rate of commission error would only be possible given a high-resolution degradation dataset of known accuracy, which does not yet exist for our study area. We can show, however, that TDX predicts a wider area of forest disturbance than the RADD alerts. This is demonstrated in Table 4, where for comparison we also include the University of Maryland (UMD) forest loss product [32] generated using optical data from the Landsat missions.

As expected, the UMD product detects much less disturbance than the radar products, as it is cloud limited and operates at too coarse a pixel size $(30 \mathrm{~m})$ to quantify selective logging. Our method using TDX appears to detect much more widespread forest disturbance than the RADD alerts, and this ratio is dependent on the temporal accuracy of the RADD alert dates (which is unknown) and the phase height decrease that is defined in this 
scenario as a disturbance. This comparison is somewhat limited by the fact that the TDX data use the statistics of a region to estimate a continuous variable (biomass loss), while the UMD and RADD systems work by classifying individual pixels as either disturbed or undisturbed. Nevertheless, it is clear that TDX phase height could have the potential to reveal lower intensities of forest degradation than these products if the false alarm rate is properly quantified.

Table 4. Total estimated area of disturbance in our study area according to TDX phase height, Radar for Detecting Deforestation (RADD) alerts generating using S-1 data, and University of Maryland (UMD) forest loss for the year 2020. TDX and RADD are analysed at different cutoffs for phase height decrease and date of detection, respectively.

\begin{tabular}{cc}
\hline Product & Predicted Area of Disturbance (ha) \\
\hline TDX $\Delta h_{\phi}<-1 \mathrm{~m}$ & 1013 \\
TDX $\Delta h_{\phi}<-1.5 \mathrm{~m}$ & 252 \\
TDX $\Delta h_{\phi}<-2 \mathrm{~m}$ & 68 \\
RADD $(01 / 01 / 20$ to $29 / 02 / 20)$ & 7 \\
RADD $(01 / 01 / 20$ to $31 / 04 / 20)$ & 13 \\
RADD $(01 / 01 / 20$ to $31 / 12 / 20)$ & 80 \\
UMD $(2020)$ & 13 \\
\hline
\end{tabular}

\subsection{Limitations}

While our method has been shown to reduce topographic artifacts in TDX $h_{\phi}$, it is yet to be shown whether it provides accurate estimates of $\triangle \mathrm{AGB}$ in areas where degradation and steep slopes coincide. The local angle of incidence should affect the penetration of X-band radar into canopy gaps, with steeper $\theta_{i}$ leading to deeper penetration [28]. It would therefore be expected that the relationship between $\Delta h_{\phi}$ and $\Delta \mathrm{AGB}$ is in turn parameterised by $\theta_{i}$. For this to be tested, temporally matching ground change data over steep slopes and satellite data would be required. Although our UAV lidar coverage includes steep terrain, no TDX acquisitions from the time of the second field campaign (January 2021) were available for comparison.

A further limitation of our $\triangle \mathrm{AGB}$ estimates is that they are restricted to a small range of values (losses between 40 and $130 \mathrm{Mg} \mathrm{ha}^{-1}$ ). This is again due to the nature of our field data, which consisted of plots which lost up to $130 \mathrm{Mg}$ of AGB. To obtain accurate estimates of landscape scale biomass change, an important step will be to include reference measurements spanning the full range from deforestation to forest regrowth. Furthermore, a larger number of ground based measurements are required to improve the statistical significance of the relationship we found. To do so, follow-up studies at this site should utilise the multi-temporal UAV lidar as a stepping stone between field measurements and satellite imagery.

In order for our method to be applicable in other regions, two other points must be considered. Firstly, in our plots, small numbers of large, merchantable trees were felled, which reflects one type of degradation seen in tropical forests, but does not match the structural changes typical of, for example, understorey clearing, fire, fuel-wood harvesting or road construction. As these changes remove different components of the forest at different heights, they will be likely to have a different effect on $\operatorname{TDX} h_{\phi}$. Therefore, to develop a general degradation model, reference measurements should include alternative forms of degradation. Secondly, we have not considered in this study the importance of initial forest height and structure. Modelling suggests the magnitude of $\triangle$ AGB for a given $\Delta h_{\phi}$ is heavily dependent on forest height [28]. Studies across different tropical forest types will therefore be necessary to develop a generalisable model of $\triangle A G B$, and methods of estimating forest height from satellite products, such as using GEDI-TDX fusion [71], will also need to be refined. 


\section{Conclusions}

$\operatorname{TDX} h_{\phi}$ is a remote sensing variable capable of measuring the relative magnitude of selective logging events in a dense tropical forest. We found a linear relationship $(r>0.99)$ between $\Delta h_{\phi}$ and biomass change in four plots where $\Delta$ AGB varied from $-28 \mathrm{Mg}^{-1}$ to $-131 \mathrm{Mg} \mathrm{ha}^{-1}$. The variation in $\Delta h_{\phi}$ amongst eleven control plots suggested that the minimum detectable change was approximately $-40 \mathrm{Mg} \mathrm{ha}^{-1}$.

Fewer looks of the radar signal (before calculating $h_{\phi}$ ) leads to the best sensitivity to forest degradation. We found the strongest relationship between $\Delta h_{\phi}$ and $\Delta$ AGB was obtained for the smallest number of looks that was tested $(3 \times 3)$. In this case, we found a sensitivity of $2.3 \mathrm{~cm} h_{\phi}$ decrease per Mg of AGB lost, which was greater than for any larger number of looks. The standard deviation of $\Delta h_{\phi}$ amongst the control plots was $66 \mathrm{~cm}$, which was more stable than for any larger number of looks.

If only a single-pass direction is available, steep terrain leads to large magnitude artifacts due to decorrelation on the slopes facing towards the SAR sensor. Neither ascending only or descending only passes showed more stability over our control plots than any method using both passes, even when the total number of images used was fixed. This can be attributed to a rapid loss of coherence with slope steepness for aspects differing from the azimuth angle by more than $90^{\circ}$.

Where multiple pass directions are available, they can be most effectively utilised through a pixel-by-pixel pass selection algorithm. The issue of decorrelation on sensorfacing slopes can be mitigated because these regions will face away from the sensor when it is passing in the opposite direction. We designed an algorithm that chose to estimate $h_{\phi}$ either from ascending or descending acquisitions, based on estimated projected local incidence angle and coherence. Our pass selection algorithm performed significantly better than a simple averaging of pass directions, producing a map of degradation that was less biased by topography, more stable at the pixel level, and more plausible considering our knowledge of the study area. The accuracy of our predicted map of $\triangle A G B$ could not be quantified due to a lack of suitable validation data, either ground or remote sensing based, but we compared it to the S-1 based RADD forest disturbance alerts and found that it suggested a higher level of degradation.

Finally, our results demonstrate that few-look TDX interferograms contain valuable information about forest structure, and highlight the vital importance of multiple SAR viewing geometries for InSAR mapping of degradation across the hilly regions of the world's tropical forests.

Author Contributions: Conceptualisation, H.C. and E.T.A.M.; Data curation, H.C., I.M., C.A. and A.B.; Formal analysis, H.C.; Funding acquisition, E.T.A.M.; Investigation, H.C., E.T.A.M., I.M., C.A., A.B., M.O.E., A.M.D. and M.D.; Methodology, H.C.; Project administration, E.T.A.M.; Software, H.C.; Supervision, E.T.A.M. and M.D.; Validation, H.C., E.T.A.M., J.-L.B.-B. and M.D.; Visualization, H.C.; Writing—original draft, H.C.; Writing—review and editing, E.T.A.M., J.-L.B.-B. and M.D. All authors have read and agreed to the published version of the manuscript.

Funding: This work was supported by European Research Council Starting Grant number 757526 awarded to Edward Mitchard: Tropical Forest Degrdation Experiment (FODEX).

Institutional Review Board Statement: Not applicable.

Informed Consent Statement: Not applicable.

Data Availability Statement: Data supporting these results is available at https://doi.org/10.608 4/m9.figshare.18545852.v1 (accessed on 3 November 2021). DLR reserve all rights to TanDEM-X imagery.

Acknowledgments: We would like to thank the staff of Rougier Gabon, including Eric Chezeaux and Evanillho Téodoro Muaño Bondjale, for hosting us in Ivindo and cooperating to make our fieldwork there possible. While in Gabon we also received invaluable support from Alfred Ngomanda, Lee White, the Agence Nationale des Parcs Nationaux (ANPN), The Ministry of Water and Forests, the Sea and the Environment, The Research Institute for Tropical Ecology (IRET), and our field assistants, 
especially Joseph Amelim Boukandja, from Ivindo community. We would also like to thank Iain Woodhouse and Mathew Brolly for their help in explaining the effects of topography on InSAR coherence, and our reviewers for their comments.

Conflicts of Interest: The authors declare no conflict of interest. The funders had no role in the design of the study; in the collection, analyses, or interpretation of data; in the writing of the manuscript, or in the decision to publish the results.

\section{References}

1. Bonan, G.B. Forests and Climate Change: Forcings, Feedbacks, and the Climate Benefits of Forests. Science 2008, 320, 1444-1449. [CrossRef]

2. $\quad$ Beer, C.; Reichstein, M.; Tomelleri, E.; Ciais, P.; Jung, M.; Carvalhais, N.; Rödenbeck, C.; Arain, M.A.; Baldocchi, D.; Bonan, G.B.; et al. Terrestrial Gross Carbon Dioxide Uptake: Global Distribution and Covariation with Climate. Science 2010, 329, 834-838. [CrossRef] [PubMed]

3. Gatti, L.V.; Basso, L.S.; Miller, J.B.; Gloor, M.; Domingues, L.G.; Cassol, H.L.; Tejada, G.; Aragão, L.E.; Nobre, C.; Peters, W.; et al. Amazonia as a carbon source linked to deforestation and climate change. Nature 2021, 595, 388-393. [CrossRef] [PubMed]

4. Hubau, W.; Lewis, S.L.; Phillips, O.L.; Affum-Baffoe, K.; Beeckman, H.; Cuní-Sanchez, A.; Daniels, A.K.; Ewango, C.E.; Fauset, S.; Mukinzi, J.M.; et al. Asynchronous carbon sink saturation in African and Amazonian tropical forests. Nature 2020, 579, 80-87. [CrossRef]

5. Mitchard, E.T. The tropical forest carbon cycle and climate change. Nature 2018, 559, 527-534. [CrossRef]

6. Baccini, A.; Walker, W.; Carvalho, L.; Farina, M.; Sulla-Menashe, D.; Houghton, R. Tropical forests are a net carbon source based on aboveground measurements of gain and loss. Science 2017, 358, 230-234. [CrossRef]

7. Houghton, R. Aboveground forest biomass and the global carbon balance. Glob. Chang. Biol. 2005, 11, 945-958. [CrossRef]

8. de Andrade, R.B.; Balch, J.K.; Parsons, A.L.; Armenteras, D.; Roman-Cuesta, R.M.; Bulkan, J. Scenarios in tropical forest degradation: Carbon stock trajectories for REDD+. Carbon Balance Manag. 2017, 12, 1-7. [CrossRef] [PubMed]

9. Herold, M.; Román-Cuesta, R.M.; Mollicone, D.; Hirata, Y.; Van Laake, P.; Asner, G.P.; Souza, C.; Skutsch, M.; Avitabile, V.; MacDicken, K. Options for monitoring and estimating historical carbon emissions from forest degradation in the context of REDD+. Carbon Balance Manag. 2011, 6, 1-7. [CrossRef] [PubMed]

10. Qin, Y.; Xiao, X.; Wigneron, J.P.; Ciais, P.; Brandt, M.; Fan, L.; Li, X.; Crowell, S.; Wu, X.; Doughty, R.; et al. Carbon loss from forest degradation exceeds that from deforestation in the Brazilian Amazon. Nat. Clim. Chang. 2021, 11, 442-448. [CrossRef]

11. Hosonuma, N.; Herold, M.; De Sy, V.; De Fries, R.S.; Brockhaus, M.; Verchot, L.; Angelsen, A.; Romijn, E. An assessment of deforestation and forest degradation drivers in developing countries. Environ. Res. Lett. 2012, 7, 12. [CrossRef]

12. Asner, G.P.; Rudel, T.K.; Aide, T.M.; Defries, R.; Emerson, R. A contemporary assessment of change in humid tropical forests. Conserv. Biol. 2009, 23, 1386-1395. [CrossRef] [PubMed]

13. Blaser, J.; Sarre, A.; Poore, D.; Johnson, S. Status of Tropical Forest Management 2011; International Tropical Timber Organization: Yokohama, Japan, 2011. Available online: https://www.itto.int/tfu/id=2686 (accessed on 3 November 2021).

14. de Wasseige, C.; Defourny, P. Remote sensing of selective logging impact for tropical forest management. For. Ecol. Manag. 2004, 188, 161-173. [CrossRef]

15. Souza, C., Jr.; Firestone, L.; Silva, L.M.; Roberts, D. Mapping forest degradation in the Eastern Amazon from SPOT 4 through spectral mixture models. Remote Sens. Environ. 2003, 87, 494-506. [CrossRef]

16. Souza, J.M.; Roberts, D. Mapping forest degradation in the Amazon region with Ikonos images. Int. J. Remote Sens. 2005, 26, 425-429. [CrossRef]

17. Asner, G.P. Cloud cover in Landsat observations of the Brazilian Amazon. Int. J. Remote Sens. 2001, 22, 3855-3862. [CrossRef]

18. Rosen, P.A.; Hensley, S.; Joughin, I.R.; Li, F.K.; Madsen, S.N.; Rodriguez, E.; Goldstein, R.M. Synthetic aperture radar interferometry. Proc. IEEE 2000, 88, 333-382. [CrossRef]

19. Reiche, J.; Mullissa, A.; Slagter, B.; Gou, Y.; Tsendbazar, N.E.; Odongo-Braun, C.; Vollrath, A.; Weisse, M.J.; Stolle, F.; Pickens, A.; et al. Forest disturbance alerts for the Congo Basin using Sentinel-1. Environ. Res. Lett. 2021, 16, 024005. [CrossRef]

20. Bouvet, A.; Mermoz, S.; Ballère, M.; Koleck, T.; Le Toan, T. Use of the SAR shadowing effect for deforestation detection with Sentinel-1 time series. Remote Sens. 2018, 10, 1250. [CrossRef]

21. Woodhouse, I.H.; Mitchard, E.T.; Brolly, M.; Maniatis, D.; Ryan, C.M. Radar backscatter is not a'direct measure'of forest biomass. Nat. Clim. Chang. 2012, 2, 556-557. [CrossRef]

22. Mermoz, S.; Réjou-Méchain, M.; Villard, L.; Le Toan, T.; Rossi, V.; Gourlet-Fleury, S. Decrease of L-band SAR backscatter with biomass of dense forests. Remote Sens. Environ. 2015, 159, 307-317. [CrossRef]

23. Lee, S.K.; Kugler, F.; Papathanassiou, K.P.; Hajnsek, I. Quantification of temporal decorrelation effects at L-band for polarimetric SAR interferometry applications. IEEE J. Sel. Top. Appl. Earth Obs. Remote Sens. 2013, 6, 1351-1367. [CrossRef]

24. Krieger, G.; Moreira, A.; Fiedler, H.; Hajnsek, I.; Werner, M.; Younis, M.; Zink, M. TanDEM-X: A satellite formation for high-resolution SAR interferometry. IEEE Trans. Geosci. Remote Sens. 2007, 45, 3317-3341. [CrossRef]

25. Solberg, S.; Lohne, T.P.; Karyanto, O. Temporal stability of InSAR height in a tropical rainforest. Remote Sens. Lett. 2015, 6, 209-217. [CrossRef] 
26. Treuhaft, R.; Lei, Y.; Gonçalves, F.; Keller, M.; Santos, J.R.d.; Neumann, M.; Almeida, A. Tropical-forest structure and biomass dynamics from TanDEM-X radar interferometry. Forests 2017, 8, 277. [CrossRef]

27. Lei, Y.; Treuhaft, R.; Keller, M.; dos Santos, M.; Gonçalves, F.; Neumann, M. Quantification of selective logging in tropical forest with spaceborne SAR interferometry. Remote Sens. Environ. 2018, 211, 167-183. [CrossRef]

28. Lei, Y.; Treuhaft, R.; Gonçalves, F. Automated estimation of forest height and underlying topography over a Brazilian tropical forest with single-baseline single-polarization TanDEM-X SAR interferometry. Remote Sens. Environ. 2021, 252, 112132. [CrossRef]

29. Kugler, F.; Schulze, D.; Hajnsek, I.; Pretzsch, H.; Papathanassiou, K.P. TanDEM-X Pol-InSAR performance for forest height estimation. IEEE Trans. Geosci. Remote Sens. 2014, 52, 6404-6422. [CrossRef]

30. Farr, T.G.; Rosen, P.A.; Caro, E.; Crippen, R.; Duren, R.; Hensley, S.; Kobrick, M.; Paller, M.; Rodriguez, E.; Roth, L.; et al. The shuttle radar topography mission. Rev. Geophys. 2007, 45. [CrossRef]

31. Turubanova, S.; Potapov, P.V.; Tyukavina, A.; Hansen, M.C. Ongoing primary forest loss in Brazil, Democratic Republic of the Congo, and Indonesia. Environ. Res. Lett. 2018, 13, 074028. [CrossRef]

32. Hansen, M.C.; Potapov, P.V.; Moore, R.; Hancher, M.; Turubanova, S.A.; Tyukavina, A.; Thau, D.; Stehman, S.V.; Goetz, S.J.; Loveland, T.R.; et al. High-resolution global maps of 21st-century forest cover change. Science 2013, 342, 850-853. [CrossRef]

33. Rozendaal, D.M.; Phillips, O.L.; Lewis, S.L.; Affum-Baffoe, K.; Alvarez-Davila, E.; Andrade, A.; Aragão, L.E.; Araujo-Murakami, A.; Baker, T.R.; Bánki, O.; et al. Competition influences tree growth, but not mortality, across environmental gradients in Amazonia and tropical Africa. Ecology 2020, 101, e03052. [CrossRef]

34. Wilson, A.M.; Jetz, W. Remotely sensed high-resolution global cloud dynamics for predicting ecosystem and biodiversity distributions. PLoS Biol. 2016, 14, e1002415. [CrossRef]

35. Philippon, N.; Cornu, G.; Monteil, L.; Gond, V.; Moron, V.; Pergaud, J.; Sèze, G.; Bigot, S.; Camberlin, P.; Doumenge, C.; et al. The light-deficient climates of western Central African evergreen forests. Environ. Res. Lett. 2019, 14, 034007. [CrossRef]

36. Adler, R.F.; Huffman, G.J.; Chang, A.; Ferraro, R.; Xie, P.P.; Janowiak, J.; Rudolf, B.; Schneider, U.; Curtis, S.; Bolvin, D.; et al. The version-2 global precipitation climatology project (GPCP) monthly precipitation analysis (1979-present). J. Hydrometeorol. 2003, 4, 1147-1167. [CrossRef]

37. Bush, E.R.; Jeffery, K.; Bunnefeld, N.; Tutin, C.; Musgrave, R.; Moussavou, G.; Mihindou, V.; Malhi, Y.; Lehmann, D.; Ndong, J.E.; et al. Rare ground data confirm significant warming and drying in western equatorial Africa. PeerJ 2020, 8, e8732. [CrossRef] [PubMed]

38. Bueso-Bello, J.L.; Gonzalez, C.; Kraus, T.; Bräutigam, B. Characteristics of TanDEM-X experimental modes. In Proceedings of the 2012 IEEE International Geoscience and Remote Sensing Symposium, Munich, Germany, 22-27 July 2012; pp. 1042-1045.

39. Phillips, O.; Baker, T.; Feldpausch, T.; Brienen, R. Field Manual for Plot Establishment and Remeasurement. RAINFOR. 2018. Available online: http:/ / www.rainfor.org/ (accessed on 3 November 2021).

40. Chave, J.; Coomes, D.; Jansen, S.; Lewis, S.L.; Swenson, N.G.; Zanne, A.E. Towards a worldwide wood economics spectrum. Ecol. Lett. 2009, 12, 351-366. [CrossRef]

41. Zanne, A.E.; Lopez-Gonzalez, G.; Coomes, D.A.; Ilic, J.; Jansen, S.; Lewis, S.L.; Miller, R.B.; Swenson, N.G.; Wiemann, M.C.; Chave, J. Global Wood Density Database. 2009. Available online: https://datadryad.org/stash/dataset/doi:10.5061/dryad.234 (accessed on 3 November 2021). [CrossRef]

42. Chave, J.; Réjou-Méchain, M.; Búrquez, A.; Chidumayo, E.; Colgan, M.S.; Delitti, W.B.; Duque, A.; Eid, T.; Fearnside, P.M.; Goodman, R.C.; et al. Improved allometric models to estimate the aboveground biomass of tropical trees. Glob. Chang. Biol. 2014, 20,3177-3190. [CrossRef]

43. Gonzalez de Tanago, J.; Lau, A.; Bartholomeus, H.; Herold, M.; Avitabile, V.; Raumonen, P.; Martius, C.; Goodman, R.C.; Disney, M.; Manuri, S.; et al. Estimation of above-ground biomass of large tropical trees with terrestrial LiDAR. Methods Ecol. Evol. 2018, 9, 223-234. [CrossRef]

44. Ploton, P.; Barbier, N.; Takoudjou Momo, S.; Réjou-Méchain, M.; Boyemba Bosela, F.; Chuyong, G.; Dauby, G.; Droissart, V.; Fayolle, A.; Goodman, R.C.; et al. Closing a gap in tropical forest biomass estimation: Taking crown mass variation into account in pantropical allometries. Biogeosciences 2016, 13, 1571-1585. [CrossRef]

45. Slik, J.F.; Paoli, G.; McGuire, K.; Amaral, I.; Barroso, J.; Bastian, M.; Blanc, L.; Bongers, F.; Boundja, P.; Clark, C.; et al. Large trees drive forest aboveground biomass variation in moist lowland forests across the tropics. Glob. Ecol. Biogeogr. 2013, 22, 1261-1271. [CrossRef]

46. Burt, A.; Boni Vicari, M.; da Costa, A.C.; Coughlin, I.; Meir, P.; Rowland, L.; Disney, M. New insights into large tropical tree mass and structure from direct harvest and terrestrial lidar. R. Soc. Open Sci. 2021, 8, 201458. [CrossRef]

47. Wilkes, P.; Lau, A.; Disney, M.; Calders, K.; Burt, A.; de Tanago, J.G.; Bartholomeus, H.; Brede, B.; Herold, M. Data acquisition considerations for terrestrial laser scanning of forest plots. Remote Sens. Environ. 2017, 196, 140-153. [CrossRef]

48. Burt, A.; Disney, M.; Calders, K. Extracting individual trees from lidar point clouds using treeseg. Methods Ecol. Evol. 2019, 10, 438-445. [CrossRef]

49. Raumonen, P.; Kaasalainen, M.; Åkerblom, M.; Kaasalainen, S.; Kaartinen, H.; Vastaranta, M.; Holopainen, M.; Disney, M.; Lewis, P. Fast automatic precision tree models from terrestrial laser scanner data. Remote Sens. 2013, 5, 491-520. [CrossRef]

50. Calders, K.; Newnham, G.; Burt, A.; Murphy, S.; Raumonen, P.; Herold, M.; Culvenor, D.; Avitabile, V.; Disney, M.; Armston, J.; et al. Nondestructive estimates of above-ground biomass using terrestrial laser scanning. Methods Ecol. Evol. 2015, 6, 198-208. [CrossRef] 
51. Momo Takoudjou, S.; Ploton, P.; Sonké, B.; Hackenberg, J.; Griffon, S.; De Coligny, F.; Kamdem, N.G.; Libalah, M.; Mofack, G.I.; Le Moguédec, G.; et al. Using terrestrial laser scanning data to estimate large tropical trees biomass and calibrate allometric models: A comparison with traditional destructive approach. Methods Ecol. Evol. 2018, 9, 905-916. [CrossRef]

52. McNicol, I. Comparisons of forest structural metrics derived from UAV LiDAR and Structure from Motion Photogrammetry under dense tropical forests. J. Geophys. Res. Biogeosci. 2021, under review.

53. Martone, M.; Bräutigam, B.; Rizzoli, P.; Gonzalez, C.; Bachmann, M.; Krieger, G. Coherence evaluation of TanDEM-X interferometric data. ISPRS J. Photogramm. Remote Sens. 2012, 73, 21-29. [CrossRef]

54. Goldstein, R.M.; Werner, C.L. Radar interferogram filtering for geophysical applications. Geophys. Res. Lett. 1998, 25, 4035-4038. [CrossRef]

55. Baran, I.; Stewart, M.P.; Kampes, B.M.; Perski, Z.; Lilly, P. A modification to the Goldstein radar interferogram filter. IEEE Trans. Geosci. Remote Sens. 2003, 41, 2114-2118. [CrossRef]

56. Bamler, R.; Hartl, P. Synthetic aperture radar interferometry. Inverse Probl. 1998, 14, R1. [CrossRef]

57. De Zan, F.; Krieger, G.; López-Dekker, P. On some spectral properties of TanDEM-X interferograms over forested areas. IEEE Geosci. Remote Sens. Lett. 2012, 10, 71-75. [CrossRef]

58. Gatelli, F.; Guamieri, A.M.; Parizzi, F.; Pasquali, P.; Prati, C.; Rocca, F. The wavenumber shift in SAR interferometry. IEEE Trans. Geosci. Remote Sens. 1994, 32, 855-865. [CrossRef]

59. Castel, T.; Martinez, J.M.; Beaudoin, A.; Wegmüller, U.; Strozzi, T. ERS INSAR data for remote sensing hilly forested areas. Remote Sens. Environ. 2000, 73, 73-86. [CrossRef]

60. Santoro, M.; Werner, C.; Wegmuller, U.; Cartus, O. Improvement of interferometric SAR coherence estimates by slope-adaptive range common-band filtering. In Proceedings of the 2007 IEEE International Geoscience and Remote Sensing Symposium, Barcelona, Spain, 23-28 July 2007; pp. 129-132.

61. Du, Y.; Feng, G.; Li, Z.; Peng, X.; Ren, Z.; Zhu, J. A Method for Surface Water Body Detection and DEM Generation With Multigeometry TanDEM-X Data. IEEE J. Sel. Top. Appl. Earth Obs. Remote Sens. 2019, 12, 151-161. [CrossRef]

62. Gao, Y.; Skutsch, M.; Paneque-Gálvez, J.; Ghilardi, A. Remote sensing of forest degradation: A review. Environ. Res. Lett. 2020, 15, 103001. [CrossRef]

63. Penman, J.; Gytarsky, M.; Hiraishi, T.; Krug, T.; Kruger, D.; Pipatti, R.; Buendia, L.; Miwa, K.; Ngara, T.; Tanabe, K.; et al. Good Practice Guidance for Land Use, Land-Use Change and Forestry; Technical Report, The Intergovernmental Panel on Climate Change National Greenhouse Gas Inventories Programme; Institute for Global Environmental Strategies: Hayama, Japan, 2003.

64. Hajnsek, I.; Moreira, A.; Zink, M.; Buckreuss, S.; Kraus, T.; Bachmann, M.; Busche, T. Tandem-X: Mission and Science. In Proceedings of the 2021 IEEE International Geoscience and Remote Sensing Symposium (IGARSS), Denver, CO, USA, 31 July-4 August 2021; pp. 789-791. [CrossRef]

65. Milillo, P.; Minchew, B.; Simons, M.; Agram, P.; Riel, B. Geodetic Imaging of Time-Dependent Three-Component Surface Deformation: Application to Tidal-Timescale Ice Flow of Rutford Ice Stream, West Antarctica. IEEE Trans. Geosci. Remote Sens. 2017, 55, 5515-5524. [CrossRef]

66. Ferretti, A.; Savio, G.; Barzaghi, R.; Borghi, A.; Musazzi, S.; Novali, F.; Prati, C.; Rocca, F. Submillimeter Accuracy of InSAR Time Series: Experimental Validation. IEEE Trans. Geosci. Remote Sens. 2007, 45, 1142-1153. [CrossRef]

67. Jin, L.; Funning, G.J. Testing the inference of creep on the northern Rodgers Creek fault, California, using ascending and descending persistent scatterer InSAR data. J. Geophys. Res. Solid Earth 2017, 122, 2373-2389. [CrossRef]

68. Schweisshelm, B.; Lachaise, M.; Fritz, T. Change Detection within the processing of the TanDEM-X Change DEM. In Proceedings of the 2021 IEEE International Geoscience and Remote Sensing Symposium (IGARSS), Brussels, Belgium, 11-16 July 2021; pp. 2130-2133.

69. ESA. Sentinel-1 Observation Scenario. 2019. Available online: https://sentinels.copernicus.eu/web/sentinel/missions/sentinel1/observation-scenario (accessed on 22 October 2021).

70. ESA. Sentinel-1 SAR User Guide. 2021. Available online: https://sentinels.copernicus.eu/web/sentinel/user-guides/sentinel-1sar (accessed on 22 September 2021).

71. Qi, W.; Lee, S.K.; Hancock, S.; Luthcke, S.; Tang, H.; Armston, J.; Dubayah, R. Improved forest height estimation by fusion of simulated GEDI Lidar data and TanDEM-X InSAR data. Remote Sens. Environ. 2019, 221, 621-634. [CrossRef] 